\title{
An Observer-Based Controller with a LMI-Based Filter against Wind-Induced Motion for High-Rise Buildings
}

\author{
Chao-Jun Chen, ${ }^{1}$ Zuo-Hua Li, ${ }^{1}$ Jun Teng, ${ }^{1}$ Wei-Hua Hu, ${ }^{1}$ and Ying Wang ${ }^{2}$ \\ ${ }^{1}$ School of Civil and Environment Engineering, Shenzhen Graduate School, Harbin Institute of Technology, Shenzhen 518055, China \\ ${ }^{2}$ Department of Civil and Environmental Engineering, University of Surrey, Guildford GU2 7XH, UK \\ Correspondence should be addressed to Zuo-Hua Li; lizuohua@hit.edu.cn
}

Received 23 December 2016; Revised 21 March 2017; Accepted 11 April 2017; Published 25 May 2017

Academic Editor: Jiming Xie

Copyright (c) 2017 Chao-Jun Chen et al. This is an open access article distributed under the Creative Commons Attribution License, which permits unrestricted use, distribution, and reproduction in any medium, provided the original work is properly cited.

\begin{abstract}
Active mass damper (AMD) control system is proposed for high-rise buildings to resist a strong wind. However, negative influence of noise in sensors impedes the application of AMD systems in practice. To reduce the adverse influence of noise on AMD systems, a Kalman filter and a linear matrix inequality- (LMI-) based filter are designed. Firstly, a ten-year return period fluctuating wind load is simulated by mixed autoregressive-moving average (MARMA) method, and its reliability is tested by wind speed power spectrum and correlation analysis. Secondly, a designed state observer with different filters uses wind-induced acceleration responses of a high-rise building as the feedback signal that includes noise to calculate control force in this paper. Finally, these methods are applied to a numerical example of a high-rise building and an experiment of a single span four-storey steel frame. Both numerical and experimental results are presented to verify that both Kalman filter and LMI-based filter can effectively suppress noise, but only the latter can guarantee the stability of AMD parameters.
\end{abstract}

\section{Introduction}

Active mass damper (AMD) is used to control the dynamic response of highly flexible buildings horizontally under environmental loadings such as strong wind [1-5]. Generally, a vector composition of displacement and velocity in the horizontal direction is used as a feedback signal for AMD control system $[6,7]$, but the whole displacements and velocities of each floor are too difficult to be measured directly. Therefore, a state observer design method is of great importance to the implementation of AMD control system in high-rise structures. The references showed the state observers can solve the problem for linear uncertain systems [8-10] and nonlinear systems [11-15]. Compared with displacement and velocity, [16] shows that the acceleration signal is easier to be measured and control system based on acceleration feedback is more robust. Unfortunately, the problem in the design process of an observer is that accelerometers may lead to a large estimation error that is regarded as noise. Therefore, filters for noise have to be considered.

At present, such filter process is often based on Kalman filter. In [17], a Kalman filter technique was used to estimate effective signal to noise ratio (SNR) in wireless sensor network (WSN) systems. Based on a maximum-likelihood criterion, Kalman filter for discrete-time systems was presented in [18]. In addition, an optimization-based adaptive Kalman filtering method was proposed in [19]. Moreover, a hybrid Kalman filter was established to denoise fiber optic gyroscope (FOG) sensors signal for discrete-time system in [20]. By unscented Kalman filter (UKF), extended Kalman filter (EKF), or particle filter (PF), the interacting multiple sensor filter (IMSF) had been presented in [21]. Similarly, based on $H_{\infty}$ filter and particle filter (PF), mixture Kalman filter (MKF) was built for conditionally linear dynamic systems in unknown non-Gaussian noises by [22]. A robust cubature Kalman filter (CKF) was designed for multisensors discretetime systems with uncertain noise variances in [23]. Generally, Kalman filter, considering the disturbance as the observation input, can be used to estimate the system state by output data and is often applied in linear, discrete-time and finite dimensional systems [24-27]. Normal Kalman filter cannot consider input excitation during state estimation. The state derivative of a general AMD control system includes the 
velocity and acceleration responses, which are closely related to the external excitation. As a result, it leads to a large estimation error when neglecting the influence of external excitation. Furthermore, since the Kalman filter is strongly dependent on the statistical properties of noise and the selected Kalman filter gain is not a global optimal solution, the problem of control forces and strokes that are oversized output in an AMD system with Kalman filter should be considered. Therefore, a new real-time filter with optimal Kalman filter gain that considers external excitation can be designed for high-rise buildings based on linear matrix inequality (LMI) approach [28].

In this paper, a state observer design method based on structural acceleration is proposed for high-rise buildings under strong wind firstly. For comparative analysis, a Kalman filter and a LMI-based filter that consider input excitation are presented to reduce the adverse influence of noise on AMD control systems. Specifically, based on variable substitution method $[29,30]$, the design problem of the LMI-based filter can be transformed into a group of nonlinear matrix inequalities, which can be turned into a group of convex and easily solved linear matrix inequalities. Finally, a numerical example of a high-rise building and an experiment of a single span four-storey steel frame are presented to verify the efficiency of the proposed filters. The result shows that only the control system with a LMI-based filter can guarantee the stability of the AMD parameters and effectively filter out noise.

\section{An Observer-Based Controller with a Filter and Numerical Verification}

2.1. An Observer-Based Controller Design. The force equilibrium of a multi-degree-of-freedom (MDOF) system is

$$
M \ddot{X}(t)+C \dot{X}(t)+K X(t)=B_{w} w(t)+B_{s} u(t),
$$

where $M, C$, and $K$ are the mass, damping, and stiffness matrix of the system, respectively. $u$ is the control force. $B_{s}$ and $B_{w}$ are the location matrices of control force and strong wind, respectively. And $\ddot{X}, \dot{X}$, and $X$ are the acceleration, velocity, and displacement of the system, respectively.

System state $Z$ includes displacement and velocity. Then, (1) can be expressed into the state-space equation as

$$
\begin{aligned}
& \dot{Z}(t)=A Z(t)+B_{1} w(t)+B_{2} u(t) \\
& Y(t)=C Z(t)+D_{1} w(t)+D_{2} u(t),
\end{aligned}
$$

where $u$ and $w$ are the control force and the input excitation, respectively. $A, B_{1}$, and $B_{2}$ are the state matrix, the excitation matrix, and the control matrix, and $C, D_{1}$, and $D_{2}$ are the state output matrix and the direct transmission matrix of excitation and control force, which can be expressed as

$$
\begin{aligned}
A & =\left[\begin{array}{cc}
0 & I \\
-M^{-1} K & -M^{-1} C
\end{array}\right], \\
B_{1} & =\left[\begin{array}{c}
0 \\
-M^{-1} B_{w}
\end{array}\right],
\end{aligned}
$$

$$
\begin{aligned}
& B_{2}=\left[\begin{array}{c}
0 \\
-M^{-1} B_{s}
\end{array}\right] \text {, } \\
& C=\left[\begin{array}{cc}
I & 0 \\
0 & I \\
-M^{-1} K & -M^{-1} C \\
0 & 0
\end{array}\right] \text {, } \\
& D_{1}=\left[\begin{array}{c}
0 \\
0 \\
-M^{-1} B_{w} \\
0
\end{array}\right] \text {, } \\
& D_{2}=\left[\begin{array}{c}
0 \\
0 \\
-M^{-1} B_{s} \\
1
\end{array}\right] \text {. }
\end{aligned}
$$

The control force of the system is

$$
u(t)=-G \cdot Z \text {. }
$$

Substituting (4) into (2) leads to

$$
\begin{aligned}
& \dot{Z}=\left(A-B_{2} G\right) Z+B_{1} w(t) \\
& Y=\left(C-D_{2} G\right) Z+D_{1} w(t),
\end{aligned}
$$

where $\bar{A}=A-B_{2} G, \bar{B}=B_{1}, \bar{C}=C-D_{2} G$, and $\bar{D}=D_{1}$. A brief form of (5) is

$$
\begin{aligned}
& \dot{Z}=\bar{A} Z+\bar{B} w \\
& Y=\bar{C} Z+\bar{D} w .
\end{aligned}
$$

The second equation of (6) can be written in the form of a partitioned matrix.

$$
\left\{\begin{array}{l}
Y_{1} \\
Y_{2}
\end{array}\right\}=\left[\begin{array}{l}
\bar{C}_{1} \\
\bar{C}_{2}
\end{array}\right] \cdot Z+\left[\begin{array}{l}
\bar{D}_{1} \\
\bar{D}_{2}
\end{array}\right] \cdot w
$$

where $Y_{1}$ is a vector of displacement and velocity of the structure and its AMD and $Y_{2}$ is a vector of acceleration, respectively. According to (7), the external excitation vector can be written as

$$
w=\bar{D}_{2}^{-1} \cdot\left(Y_{2}-\bar{C}_{2} Z\right) .
$$

Substituting (8) into (6) and (7) leads to

$$
\begin{aligned}
\dot{Z} & =\left(\bar{A}-\bar{B} \bar{D}_{2}^{-1} \bar{C}_{2}\right) Z+\bar{B} \bar{D}_{2}^{-1} Y_{2} \\
Y_{1} & =\left(\bar{C}_{1}-\bar{D}_{1} \bar{D}_{2}^{-1} \bar{C}_{2}\right) Z+\bar{D}_{1} \bar{D}_{2}^{-1} Y_{2},
\end{aligned}
$$

where $\widetilde{A}=\bar{A}-\bar{B} \bar{D}_{2}^{-1} \bar{C}_{2}, \widetilde{B}=\bar{B} \bar{D}_{2}^{-1}, \widetilde{C}=\bar{C}_{1}-\bar{D}_{1} \bar{D}_{2}^{-1} \bar{C}_{2}$, and $\widetilde{D}=\bar{D}_{1} \bar{D}_{2}^{-1}$. 


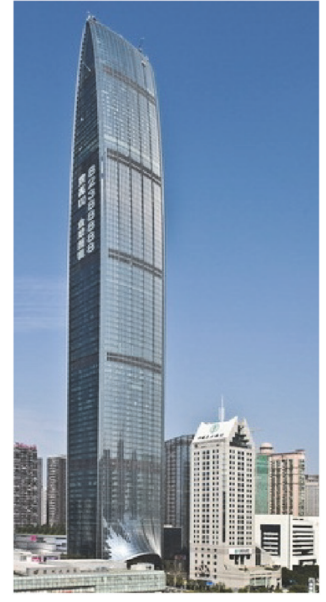

(a)

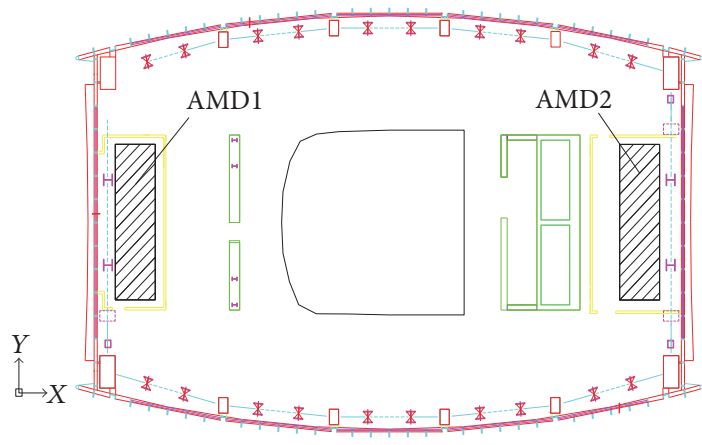

(b)

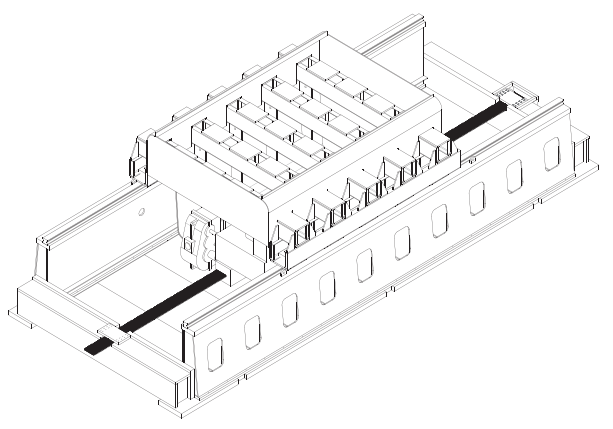

(c)

FIGURE 1: KK100 and its AMD systems: (a) picture of the building; (b) locations of the AMD systems; (c) an AMD system.

Equation (9) can be written as

$$
\begin{aligned}
\dot{Z} & =\widetilde{A} Z+\widetilde{B} Y_{2} \\
Y_{1} & =\widetilde{C} Z+\widetilde{D} Y_{2} .
\end{aligned}
$$

The state observer is

$$
\begin{aligned}
\dot{Z} & =\widetilde{A} Z+\widetilde{B} Y_{2}+G_{o}\left(Y_{1}-\widetilde{Y}_{1}\right) \\
\widetilde{Y}_{1} & =\widetilde{C} Z+\widetilde{D} Y_{2} .
\end{aligned}
$$

Substituting the second equation of (11) into the first equation leads to

$$
\begin{aligned}
\dot{Z} & =\left(\widetilde{A}-G_{o} \widetilde{C}\right) Z+\left(\widetilde{B}-G_{o} \widetilde{D}\right) Y_{2}+G_{o} Y_{1} \\
\widetilde{Y}_{1} & =\widetilde{C} Z+\widetilde{D} Y_{2},
\end{aligned}
$$

where $G_{o}$ is the feedback gain of the observer. $Y_{2}$ and $Z$ can be used to estimate the estimated states $\widetilde{Y}_{1}$ of the structure and its AMD. $\widetilde{Y}_{1}$ is then used to calculate the control force.

\subsection{The Simulation of Wind-Induced Motions of a High-Rise} Building. In this paper, a high-rise building called KingKey Financial Center (KK100) shown in Figure 1(a) has a height of $441.8 \mathrm{~m}$, and its slenderness ratio is 10.2. Its structural periods and frequencies are listed in Table 1. Moreover, the lumped mass method is used for establishing the mass matrix of KK100 whose total mass is $5.79 \times 10^{5}$ tons. Its stiffness matrix that has taken into account structural flexural and shear deformations is built based on unit-displacement method, and its structural damping ratio is 0.015 . The first four natural mode shapes of KK100 along the minor-axis are given in Figure 2.

Its AMD control system shown in Figures 1(b) and 1(c) includes two sets of synchronous AMD devices, which are located on both sides of the 91st floor, mainly used for the controlling wind-induced motion along the minor-axis. The parameters of the control system are listed in Table 2.
TABLE 1: The periods and frequencies of KK100.

\begin{tabular}{lcc}
\hline Vibration mode & Periods (s) & Frequencies $(\mathrm{Hz})$ \\
\hline 1 & 7.1522 & 0.1398 \\
2 & 1.9490 & 0.5131 \\
3 & 0.9525 & 1.0499 \\
4 & 0.6445 & 1.5516 \\
\hline
\end{tabular}

TABLE 2: Key parameters of the AMD system.

\begin{tabular}{lc}
\hline Index & AMD \\
\hline Auxiliary mass $(\mathrm{t})$ & $250 \times 2$ \\
Effective stroke $(\mathrm{m})$ & \pm 2.2 \\
Peak power $(\mathrm{kW})$ & $300 \times 2$ \\
Maximum driving force $(\mathrm{kN})$ & $275 \times 2$ \\
\hline
\end{tabular}

KK100 is located in Caiwuwei Financial Center, Luohu District, Shenzhen, China. According to the Chinese loads code on buildings, the roughness category of the area is $\mathrm{C}$ and the basic wind pressure of ten-year return period is $0.45 \mathrm{kN} / \mathrm{m}^{2}$. Based on Davenport spectrum, a fluctuating wind speed can be generated. The power spectral density of fluctuating wind speed is decreased as the following equation.

$$
\begin{aligned}
S_{u}(f) & =4 k \bar{V}^{2}(10) \frac{x^{2}}{f\left(1+x^{2}\right)^{4 / 3}} \\
x & =1200 \frac{f}{\bar{V}(10)},
\end{aligned}
$$

where $\bar{V}(10)$ is the average wind speed at a height of $10 \mathrm{~m}$ above ground level and $f$ is the frequency of the fluctuating wind, respectively. $k$ is the coefficient related to ground roughness and can be expressed as

$$
k=\frac{1}{6 \times 8.8^{2}} \times 35^{3.6(\alpha-0.16)},
$$

where $\alpha=0.22$ is the $\mathrm{C}$ category ground roughness exponent. 


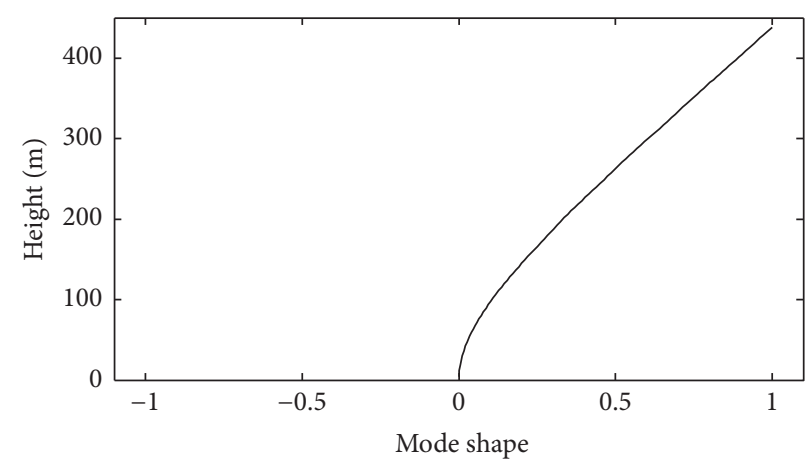

(a)

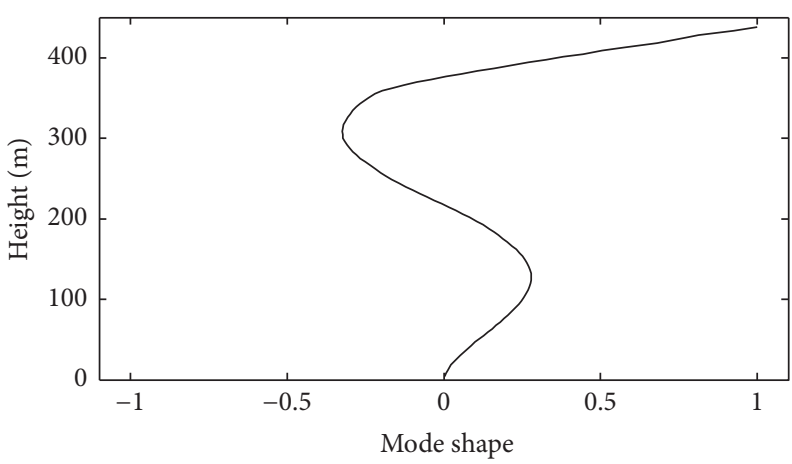

(c)

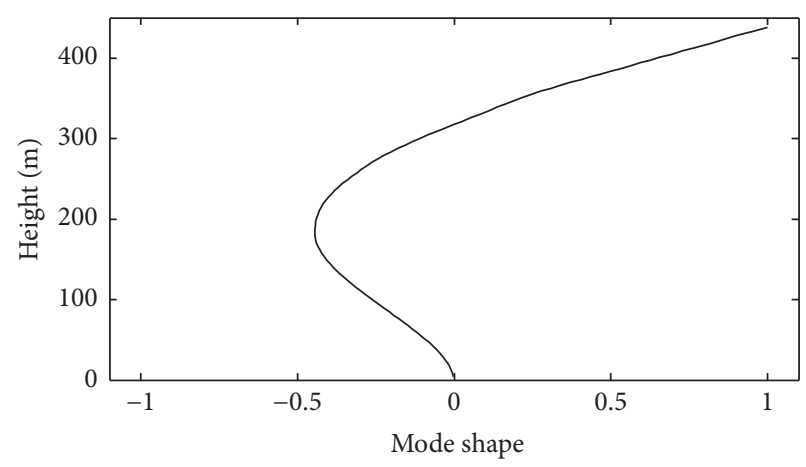

(b)

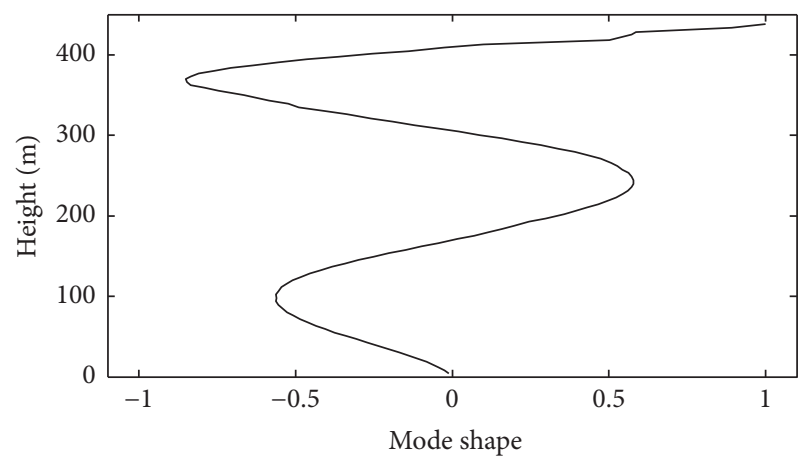

(d)

Figure 2: Mode shapes of KK100: (a) Mode 1; (b) Mode 2; (c) Mode 3; (d) Mode 4.

The spatial correlation of fluctuating wind in time domain is mainly related to transverse and vertical correlation and is represented by correlation function. In frequency domain, the coherence function is used to describe the spatial correlation. Compared with the vertical dimension of KK100, the lateral dimension is relatively small. Therefore, the vertical correlation of fluctuating wind load is only considered. The coherence coefficient of fluctuating wind pressure in vertical direction is

$$
\rho_{z}\left(z_{1}, z_{2}\right)=e^{\left(-\left|z_{1}-z_{2}\right| / L_{z}\right)},
$$

where $\left|z_{1}-z_{2}\right|$ is the distance between two floors in vertical direction and $L_{z}=60 \mathrm{~m}$ according to Chinese loads code on buildings.

Mixed autoregressive-moving average (MARMA) model [31] is proposed to simulate the stochastic process. A stochastic wind speed time series can be generated as

$$
\begin{aligned}
{[U(t)] } & =\left[u_{1}(t), u_{2}(t), \ldots, u_{m}(t)\right]^{T} \\
& =\sum_{k=1}^{p}\left[\Psi_{k}\right][U(t-k \Delta t)]+N(t),
\end{aligned}
$$

where

$$
\begin{aligned}
& {[U(t-k \Delta t)]} \\
& \quad=\left[u_{1}(t-k \Delta t), u_{2}(t-k \Delta t), \ldots, u_{m}(t-k \Delta t)\right]^{T} \\
& N(t)=\left[N_{1}(t), N_{2}(t), \ldots, N_{m}(t)\right]^{T},
\end{aligned}
$$

where $u_{i}(t-k \Delta t)$ is the wind speed of the $i$ th random wind speed time series at time $(t-k \Delta t)$ and $p$ is the order of autoregressive model. $N_{i}(t)$ is a zero mean random number series that obeys normal distribution with a given covariance $R_{u}$, respectively. The relationship between power spectral density and covariance satisfies Wiener-Khintchine approach that can be described as

$$
R_{u}^{i}(k \Delta t)=\int_{0}^{\infty} S_{u}^{i}(f) \cos (2 \pi k \Delta t f) d f .
$$

$R_{u}$ can be obtained by (18), and $\left[\Psi_{k}\right]$ is a regression coefficient matrix based on $R_{u}$. Equation (16) can be separated by time $\Delta t$, and the recursive matrix is expressed as

$$
\begin{aligned}
{\left[\begin{array}{c}
u_{1}(j \Delta t) \\
\vdots \\
u_{m}(j \Delta t)
\end{array}\right] } & \sum_{k=1}^{p}\left[\Psi_{k}\right]\left[\begin{array}{c}
u_{1}[(j-k) \Delta t] \\
\vdots \\
u_{m}[(j-k) \Delta t]
\end{array}\right] \\
& +\left[\begin{array}{c}
N_{1}(j \Delta t) \\
\vdots \\
N_{m}(j \Delta t)
\end{array}\right],\left[\begin{array}{c}
j \Delta t=0, \ldots, T \\
k \leq j
\end{array}\right] .
\end{aligned}
$$

Discrete fluctuating wind speed vectors with a timeinterval $\Delta t$ can be derived from (19). In order to test the reliability of the simulation results, the Fourier transformation is applied to finish wind speed power spectrum and 


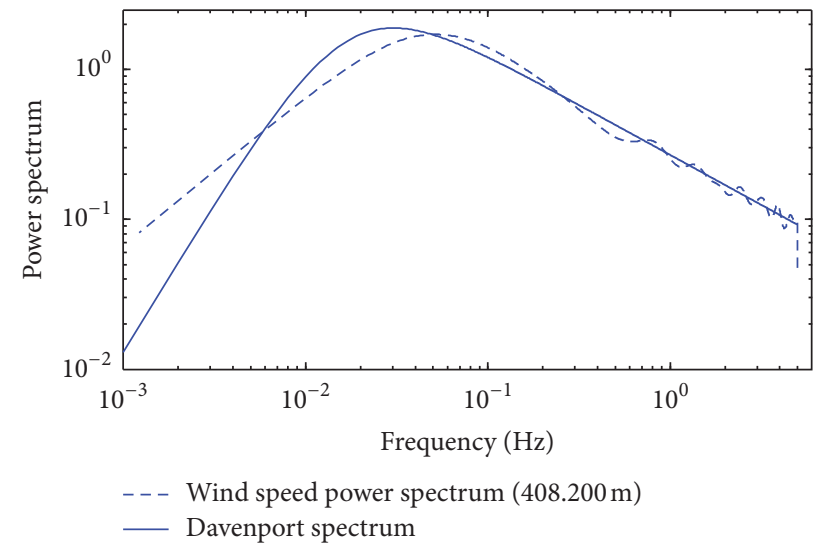

(a)

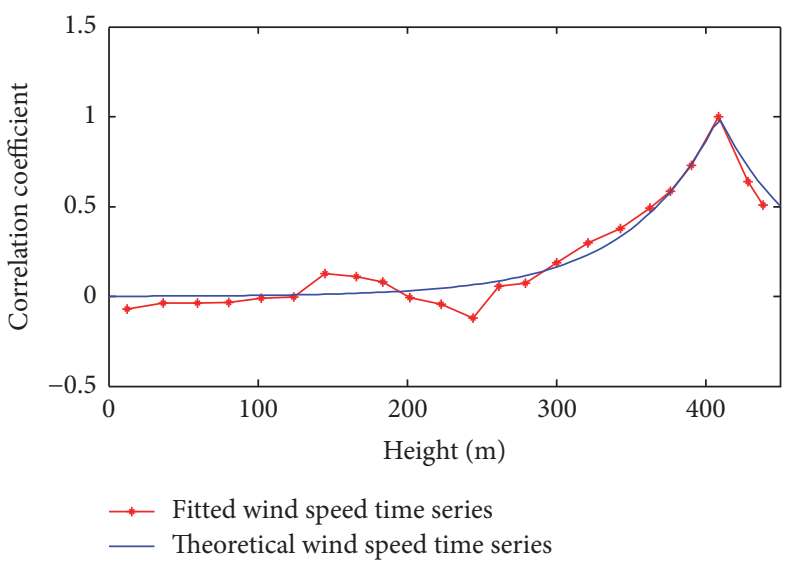

(b)

Figure 3: Tests of the fluctuating wind speed time series on 92nd floor (408.200 m): (a) wind speed power spectrum test; (b) correlation test.

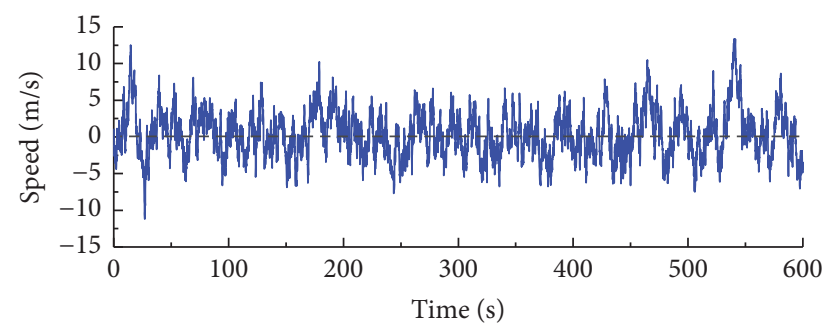

FIGURE 4: A ten-year return period fluctuating wind speed time series on 92 nd floor $(408.200 \mathrm{~m})$.

correlation tests shown in Figure 3. Figure 3(a) shows that spectrum analysis of the simulated fluctuating wind speed based on MARMA method is similar to Davenport spectrum in a wide frequency band $\left(f \geqslant 10^{-2} \mathrm{~Hz}\right)$. It covers the natural frequency of high-rise buildings. Figure 3(b) indicates the vertical correlation of two kinds of fluctuating wind speed time series is high goodness-of-fit.

Following these above steps, the fluctuating wind speed time series of each floor can be generated along the height of KK100. Time-history curve of the fluctuating wind speed on 92nd floor (at $408.200 \mathrm{~m}$ above ground) is shown in Figure 4. As the fluctuating wind speed and structural information have been given, the simulated fluctuating wind load on each floor of KK100 can be calculated by (20). Time-history curve of the ten-year return period simulated fluctuating wind load on 92nd floor is shown in Figure 5. The simulated wind load is only used for numerical analysis in the paper, and it cannot represent the realistic wind load of KK100.

$$
P_{i}=\rho \bar{V}(z) u_{i}(z, t) \mu_{s} S
$$

where $P_{i}$ is the fluctuating wind load at $i$ th floor and $\rho$ is the air density. $\bar{V}(z)$ is the average wind speed at $i$ th floor. $u_{i}$ is the fluctuating wind speed that is associated with height and time. $\mu_{s}$ and $S$ are the shape factor of a building and the area of windward side, respectively.

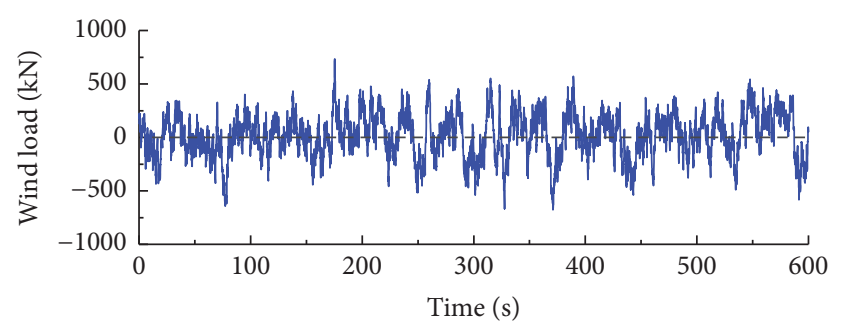

FIGURE 5: A ten-year return period fluctuating wind load on 92nd floor $(408.200 \mathrm{~m})$.

An observer-based controller shown in Figure 6(a) and an original controller shown in Figure 6(b) are designed to suppress the wind-induced motions of KK100. The structural acceleration of the 87th floor under uncontrolled and controlled scenarios is shown in Figure 7, and AMD parameters of different systems are shown in Figure 8. Table 3 presents the control effects and values of AMD parameters. In this paper, control effect is quantified as the ratio between structural response reduction and the structural response without control, and $A M D$ parameters include control force and stroke. From Figures 7 and 8, the original controller and the observer-based controller can obviously reduce the wind vibration response. The frequencies of KK100 in different vibration modes are obtained and nicely consistent with its theoretical values listed in Table 1. For example, its natural frequency shown in Figure 7(d) is $0.1399 \mathrm{~Hz}$ in line with its theoretical value $(0.1398 \mathrm{~Hz})$. Moreover, the maximum variations of the displacement and acceleration control effects between two different systems are only $0.0012 \%$ and $0.0712 \%$, and the AMD parameters of the state observer increase by $-7.6087 \mathrm{kN}$ and $0.0001 \mathrm{~m}$. In a word, the observer-based controller is used instead of the original controller, in order to overcome the difficulty in direct measurement of the state vector that includes both structural displacements and velocities in the horizontal direction of KK100. 


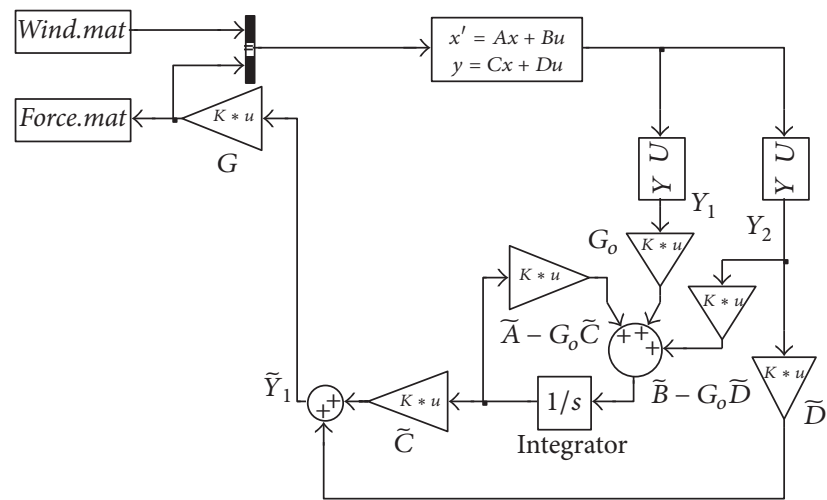

(a)

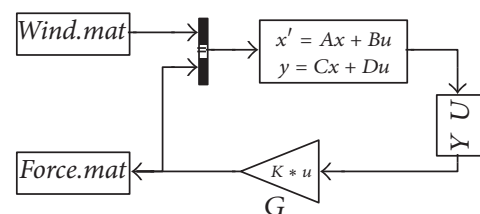

(b)

FIGURE 6: Simulink module of the control systems: (a) an observer-based controller; (b) an original controller.

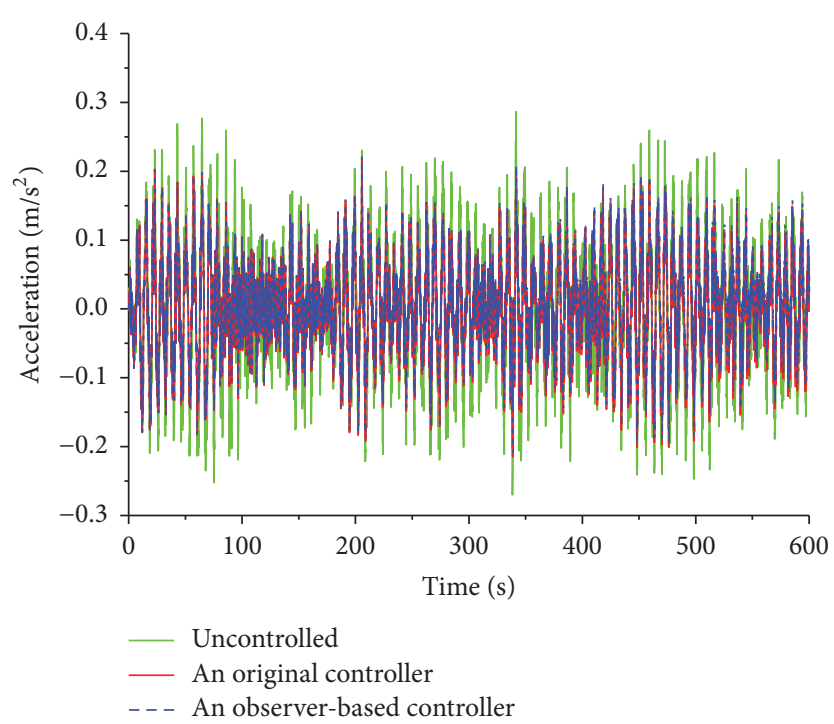

(a)

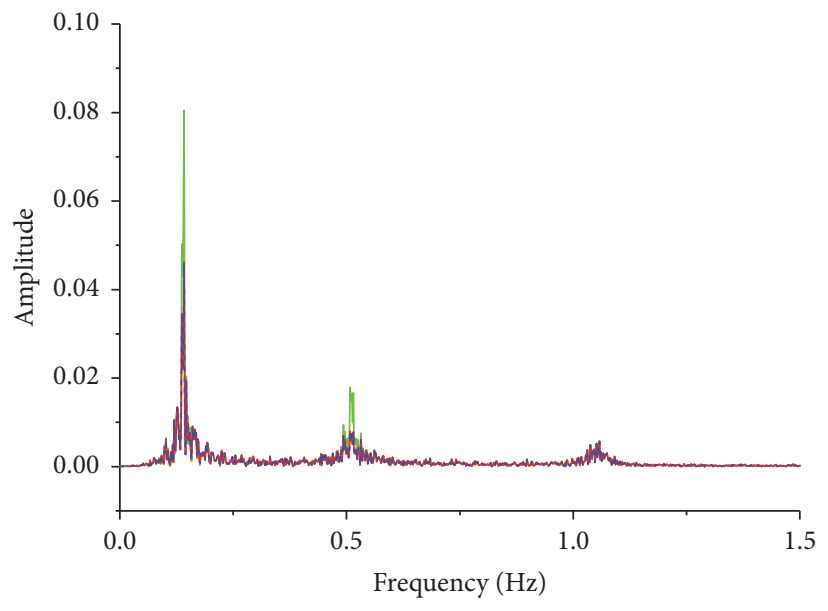

Uncontrolled

An original controller

- . - An observer-based controller

(c)

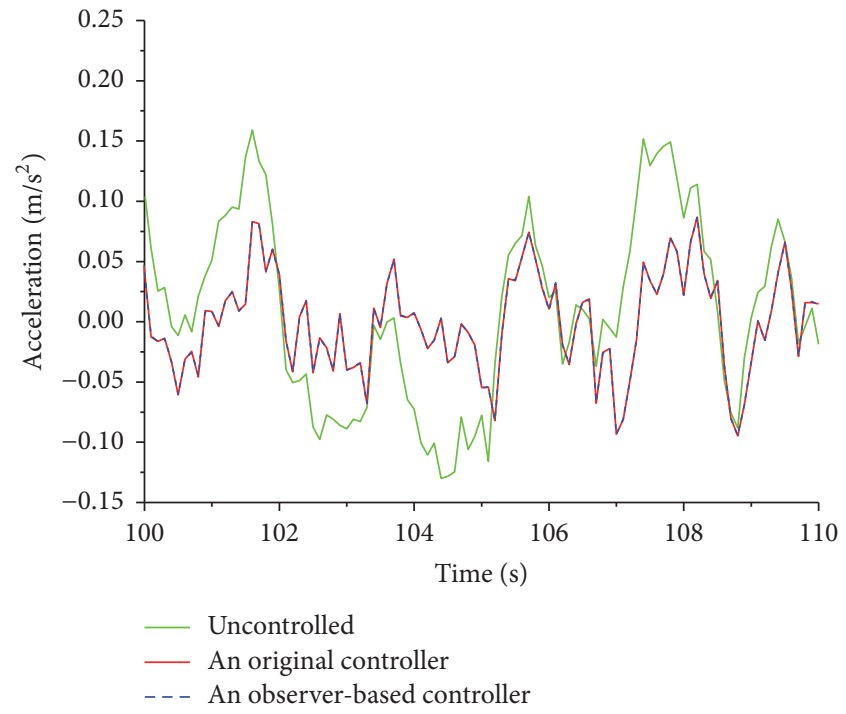

(b)

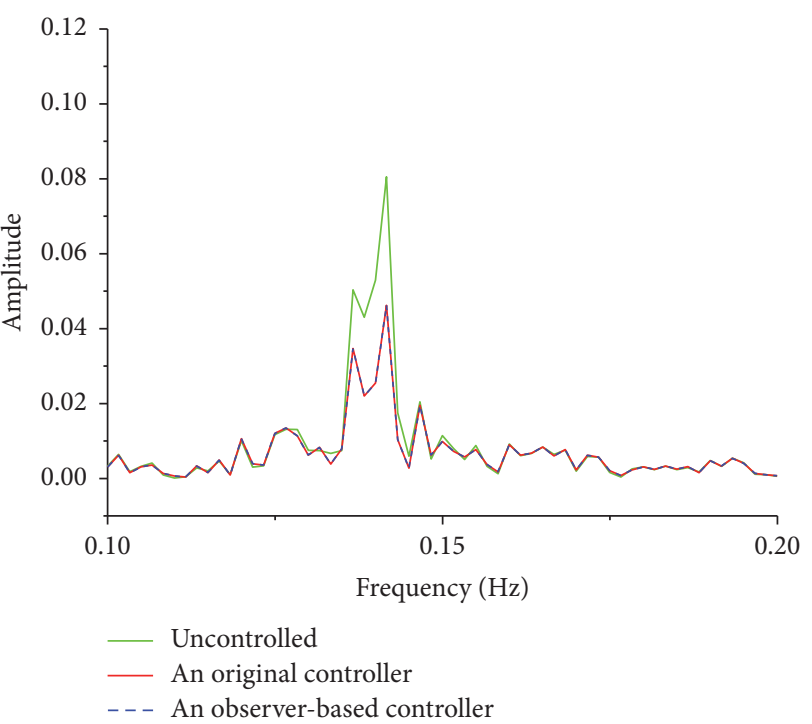

(d)

FIGURE 7: Comparison of structural acceleration in 87th floor under uncontrolled and controlled scenarios: (a) and (b) time domain; (c) and (d) frequency domain. 


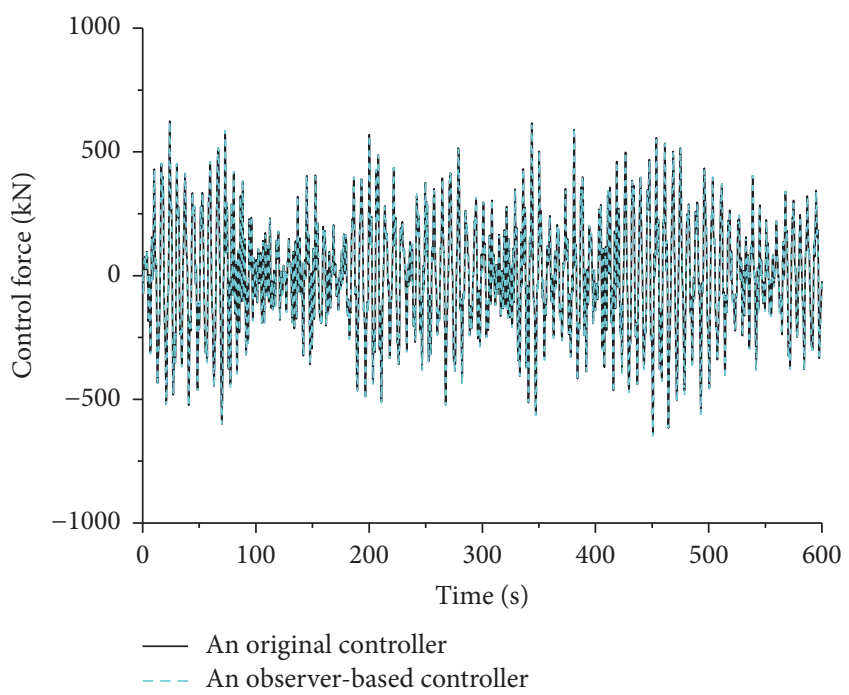

(a)

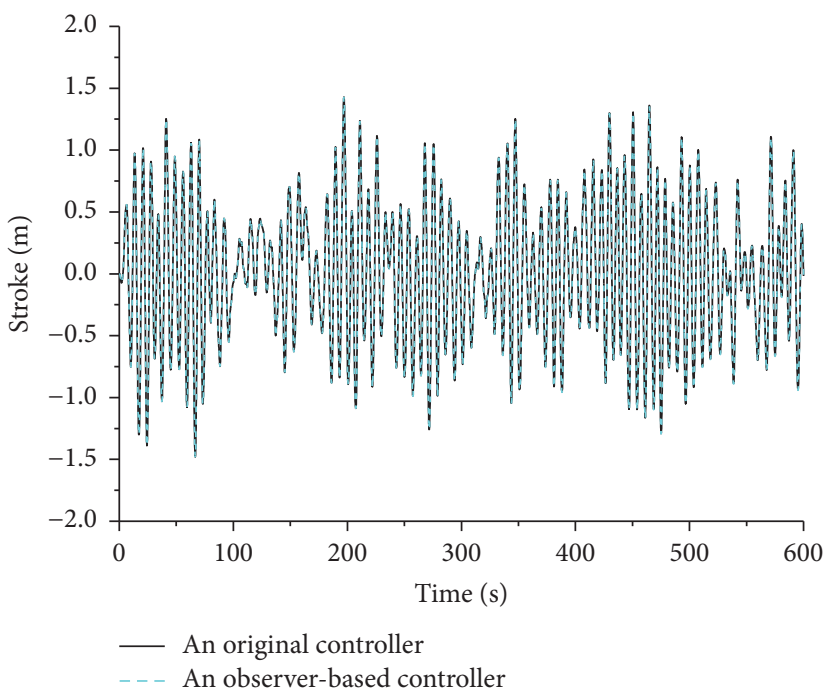

(b)

FIGURE 8: Comparison of AMD parameters: (a) AMD control forces; (b) AMD strokes.

TABLE 3: Control effectiveness of structural responses.

\begin{tabular}{lcccc}
\hline \multicolumn{1}{c}{ Index } & & An original controller & An observer-based controller & Error \\
\hline Displacement control effect (\%) & 87th floor & 28.1909 & 28.1897 & 0.0012 \\
& 91 st floor & 28.2056 & 28.2044 & 0.0012 \\
& 87th floor & 28.7039 & 28.6327 & 0.0712 \\
Acceleration control effect (\%) & 91st floor & 27.5019 & 27.4487 & 0.0532 \\
AMD control forces (kN) & & 638.2055 & 645.8142 & -7.6087 \\
AMD strokes (m) & & 1.4769 & 1.4768 & 0.0001 \\
\hline
\end{tabular}

2.3. A Kalman Filter Design. When the external excitation is not taken into account, the state-space equation of a MDOF control system with noise can be described as

$$
\begin{aligned}
& \dot{Z}(t)=A Z(t)+B_{2} u(t)+w_{1}(t) \\
& Y(t)=C Z(t)+D_{2} u(t)+w_{2}(t),
\end{aligned}
$$

where $w_{1}$ and $w_{2}$ are random process noise and measurement noise, respectively, and are assumed to be independent. Covariance matrices [18] of these Gaussian noises are

$$
\begin{aligned}
& Q=E\left[w_{1}(t) \cdot w_{1}(t)^{T}\right], \\
& R=E\left[w_{2}(t) \cdot w_{2}(t)^{T}\right],
\end{aligned}
$$

where $E(\cdot)$ is the expectation value of $(\cdot)$.

The control force is

$$
u(t)=-G Z(t) .
$$

Substituting (23) into (21) leads to

$$
\begin{aligned}
& \dot{Z}(t)=\left(A-B_{2} G\right) Z(t)+w_{1}(t) \\
& Y(t)=\left(C-D_{2} G\right) Z(t)+w_{2}(t) .
\end{aligned}
$$

A Kalman filter [32] for control systems can be constructed as

$$
\begin{aligned}
\dot{\widehat{Z}}(t) & =\left(A-B_{2} G\right) \widehat{Z}(t)+G_{f}(Y-\widehat{Y}) \\
\widehat{Y}(t) & =\left(C-D_{2} G\right) \widehat{Z}(t)
\end{aligned}
$$

where $G_{f}$ is the Kalman filter gain, $\widehat{Z}$ is the optimal estimation of the state, and $\widehat{Y}$ is the observation, respectively. According to [33], the Kalman filter gain can be written as

$$
G_{f}=P_{e}\left(C-D_{2} G\right)^{T} R^{-1}
$$

where $P_{e}$ is the model state error covariance matrix and can be solved by the following Riccati equation

$$
\begin{aligned}
P_{e} A^{T} & +A P_{e}-P_{e}\left(C-D_{2} G_{c}\right)^{T} R^{-1}\left(C-D_{2} G_{c}\right) P_{e} \\
& +Q=0 .
\end{aligned}
$$

Note that the Kalman filter shown by (25) ignores the influence of external excitation during the system state estimation. However, the derivative of state vectors of a general 
AMD control system includes the velocity and acceleration responses, which are closely related to the external excitation. Therefore, it leads to a large estimation error when neglecting the influence of external excitation. In order to ensure that the Kalman filter can effectively correct the system state estimation values, the output of the filter includes displacement and velocity responses.

The rebuilt state-space equation of the control system is

$$
\begin{aligned}
& \dot{Z}(t)=\left(A-B_{2} G\right) Z(t)+B_{1} w(t)+w_{1}(t) \\
& Y(t)=Z(t)+w_{2}(t) .
\end{aligned}
$$

In a linear system, the relationship between external excitation $w$ and state vector $Z$ is

$$
w=H Z,
$$

where $H$ is an unknown transfer function matrix.

Substituting (29) into (28) leads to

$$
\begin{aligned}
& \dot{Z}(t)=\left(A-B_{2} G+B_{1} H\right) Z(t)+w_{1}(t) \\
& Y(t)=Z(t)+w_{2}(t) .
\end{aligned}
$$

Equation (30) is transformed into a discrete system.

$$
\begin{aligned}
& Z(k+1)=e^{\varepsilon\left(A-B_{2} G+B_{1} H\right)} Z(k)+w_{1}(k+1) \\
& Y(k+1)=Z(k+1)+w_{2}(k+1),
\end{aligned}
$$

where $\varepsilon$ is a time-step.

According to [34], a Kalman filter of discrete systems is

$$
\begin{aligned}
\widehat{Z}(k+1)= & \widetilde{Z}(k+1)+G_{f k+1}[Y(k+1)-\widehat{Y}(k+1)] \\
\widetilde{Z}(k+1)= & \Phi(k) \widehat{Z}(k) \\
\Phi(k)= & e^{\varepsilon\left(A-B G+B_{1} H\right)} \\
\widehat{Y}(k+1)= & \widehat{Z}(k+1) \\
Y(k+1)= & \widehat{Y}(k) \\
G_{f k+1}= & \widetilde{P}_{k+1}\left[\widetilde{P}_{k+1}+R\right]^{-1} \\
\widetilde{P}_{k+1}= & \Phi(k) \widehat{P}_{k}[\Phi(k)]^{T}+Q_{k} \\
\widehat{P}_{k+1}= & {\left[I-G_{f k+1}\right] \widetilde{P}_{k+1}\left[I-G_{f k+1}\right]^{T} } \\
& +G_{f k+1} R G_{f k+1}^{T},
\end{aligned}
$$

where $\Phi(k)$ is the state transition matrix. $\widetilde{Z}(k)$ and $\widehat{Z}(k)$ are the estimates of the state $Z(k)$ before and after correction. $\widetilde{P}_{k}$ and $\widehat{P}_{k}$ are the estimates of model state error covariance matrix before and after correction.
Since the discrete filter shown (32) contains an uncertain coefficient matrix $H$, it still cannot be used in practice. In general, $\varepsilon$ is sufficiently short and $\|H\|<\infty$; thus

$$
\lim _{\delta \rightarrow 0}[\Phi(k)]=\lim _{\Delta t \rightarrow 0} e^{\varepsilon\left(A-B_{2} G+B_{1} H\right)}=e^{0}=I .
$$

The discrete filter shown (32) can be written as

$$
\begin{aligned}
\widehat{Z}(k+1)= & \widehat{Z}(k)+G_{f k+1}[Y(k+1)-\widehat{Y}(k+1)] \\
\widehat{Y}(k+1)= & \widehat{Z}(k+1) \\
G_{f k+1}= & \widetilde{P}_{k+1}\left(\widetilde{P}_{k+1}+R\right)^{-1} \\
\widetilde{P}_{k+1}= & \widehat{P}_{k}+Q_{k} \\
\widehat{P}_{k+1}= & \left(I-G_{f k+1}\right) \widetilde{P}_{k+1}\left(I-G_{f k+1}\right)^{T} \\
& +G_{f k+1} R G_{f k+1}^{T} .
\end{aligned}
$$

A Simulink block diagram of the rebuilding control system with a Kalman filter shown in Figure 9 is designed to filter noise. The state observer is depicted by the dashed box, and the symbol inside the solid box represents the Kalman filter.

In this paper, a measured acceleration signal in 87th floor has been collected by the health monitoring system of KK100. This signal includes noise and is processed by wavelet transformation to acquire the actual part of the structural acceleration. Thus, the characteristics of a special noise can be understood. Based on the measured and the actual acceleration signal, the estimate of the state can be obtained by the state observer, and the difference between the actual state $Z$ and the estimated state $\widehat{Z}$ is defined as the measurement noise $w_{2}$ of the system. Therefore, covariance matrix of the measurement noise $R$ can be solved. Additionally, since the output of the Kalman filter is the system state, $Q=R$ is set up.

Based on the above obtained covariance matrices $Q$ and $R$, under a ten-year return period wind load, three systems can be established for KK100. System 1 does not contain noise, systems 2 and 3 include noise, and system 3 with a Kalman filter should be considered. The structural acceleration of different control systems is shown in Figure 10, and the corresponding control effects are listed in Table 4. Figure 10 indicates the control system with noise that does not take any measure is to diverge, and the acceleration control effects of different floors are negative. Compared with the control system without noise, the control system with filtering noise can also obviously reduce the acceleration response of the structure. From Table 4, the maximum variations of the control effects between System 1 and System 3 are only $0.8150 \%$ and $1.0505 \%$, meaning the control effects are equivalent to the former. The fact can prove the effectiveness of the Kalman filter.

According to (26) and (27), a Kalman filter gain of linear continuous-time systems should be solved by a model state error covariance matrix $P_{e}$, covariance matrices of random process noise, and measurement noises $Q$ and $R$. Based on the above statistics, $P_{e}$ is used to calculate the Kalman gain 


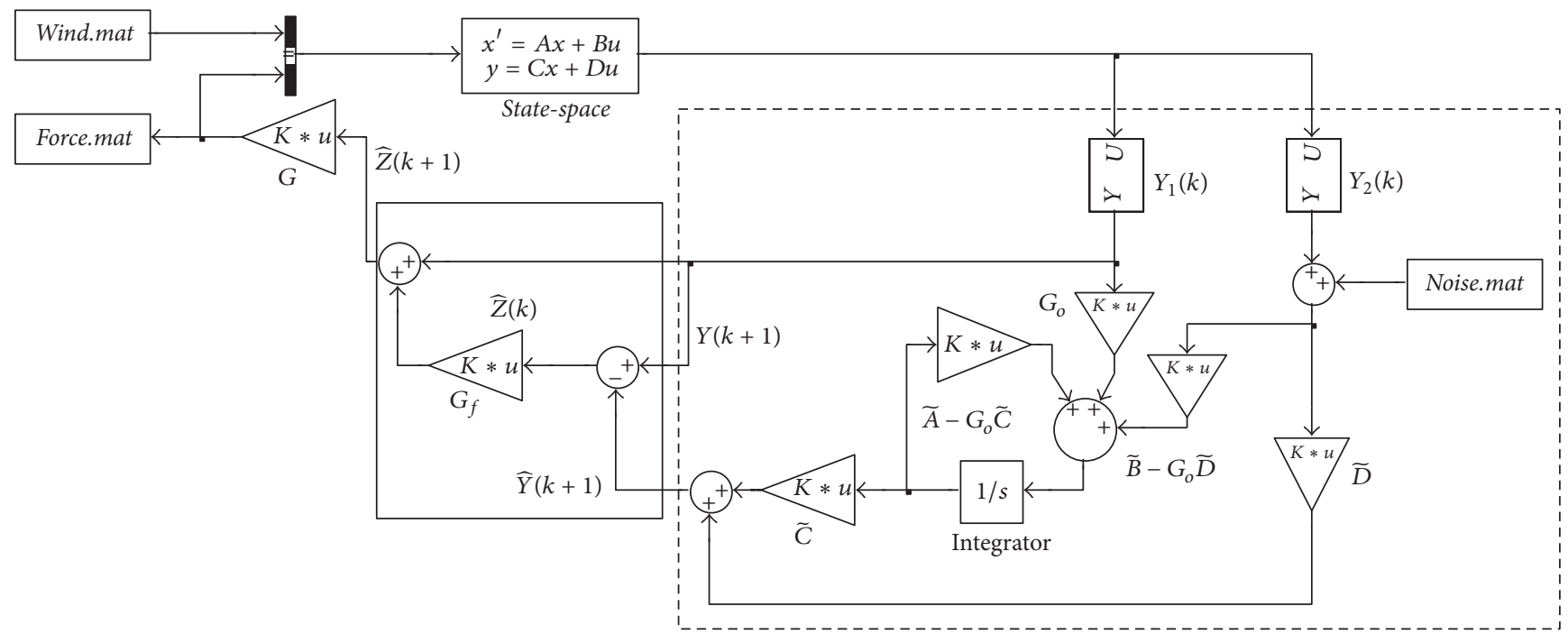

FIGURE 9: Simulink block diagram of the system with a Kalman filter.

TABLE 4: Comparison of the acceleration control effects (\%).

\begin{tabular}{lccc}
\hline Floor & System 1 & System 2 & System 3 (Kalman filter) \\
\hline 87th & 29.4691 & -24.5848 & 28.6541 \\
91st & 28.2815 & -12.5420 & 27.2310 \\
\hline
\end{tabular}

of discrete systems; this process has been shown by (34). These above methods do not contain selection process for an optimal gain. Since the selected Kalman filter gain is not a global optimal solution, the observed control force and stroke of system 3 display in Figure 11 are diverging as time goes on. When the absolute value of the AMD stroke is maximum $(-3.07 \mathrm{~m})$, its AMD speed is up to $(-0.90 \mathrm{~m} / \mathrm{s})$. Obviously, a real-time robust filter with optimal gain needs to be designed based on LMI approach to solve this problem.

2.4. A LMI-Based Filter Design. When the output contains displacement and velocity responses, the state-space equation of the Kalman filter can be written as

$$
\begin{aligned}
\dot{\widehat{Z}}(t) & =\left(A-B_{2} G\right) \widehat{Z}(t)+G_{f}(Y-\widehat{Y}) \\
\widehat{Y}(t) & =\widehat{Z}(t) .
\end{aligned}
$$

Subtracting the first equation in (28) from the first equation in (35), the residue equation is then defined as

$$
\begin{aligned}
\Delta \dot{Z}(t)= & {\left[\left(A-B_{2} G\right)-G_{f}\right] \Delta Z(t)+B_{1} w(t) } \\
& +\left[w_{1}(t)-G_{f} w_{2}(t)\right],
\end{aligned}
$$

where $\Delta Z(t)$ is the state of the residue equation and $\Delta Z(t)=$ $Z(t)-\widehat{Z}(t)$.
Define

$$
\begin{aligned}
\widehat{A} & =A-B_{2} G-G_{f} \\
\widehat{B} & =\left[B_{1}, I,-G_{f}\right] \\
\xi(t) & =\left[w(t)^{T}, w_{1}(t)^{T}, w_{2}(t)^{T}\right]^{T} .
\end{aligned}
$$

From (37), the residue equation is

$$
\begin{aligned}
\Delta \dot{Z}(t) & =\widehat{A} \Delta Z(t)+\widehat{B} \xi(t) \\
Y(t) & =\Delta Z(t) .
\end{aligned}
$$

$\gamma$ is a given positive constant. In [35], if and only if there exists a symmetric positive-definite matrix $X_{1}$ such that the following inequality holds, then the control system shown as (38) has a $H_{\infty}$ state feedback filter.

$$
\left[\begin{array}{ccc}
\widehat{A} X_{1}+X_{1} \widehat{A}^{T} & \widehat{B} & X_{1} \\
\widehat{B}^{T} & -\gamma I & 0 \\
X_{1} & 0 & -\gamma I
\end{array}\right]<0 .
$$

$\eta$ is a given positive constant. In [29], if and only if there exists symmetric positive-definite matrices $X_{2}$ and $Q$ such that the following inequalities hold, then the control system shown as (38) has a $\mathrm{H}_{2}$ state feedback filter.

$$
\begin{array}{r}
\widehat{A} X_{2}+X_{2} \widehat{A}^{T}+\widehat{B} \widehat{B}^{T}<0, \\
{\left[\begin{array}{cc}
-Q & X_{2} \\
X_{2} & -X_{2}
\end{array}\right]<0} \\
\operatorname{trace}(Q)<\eta^{2}
\end{array}
$$

The first inequality of inequalities (40) can be satisfied by inequality (39). The variables $X_{1}, X_{2}, Q$, and $G_{f}$ are 

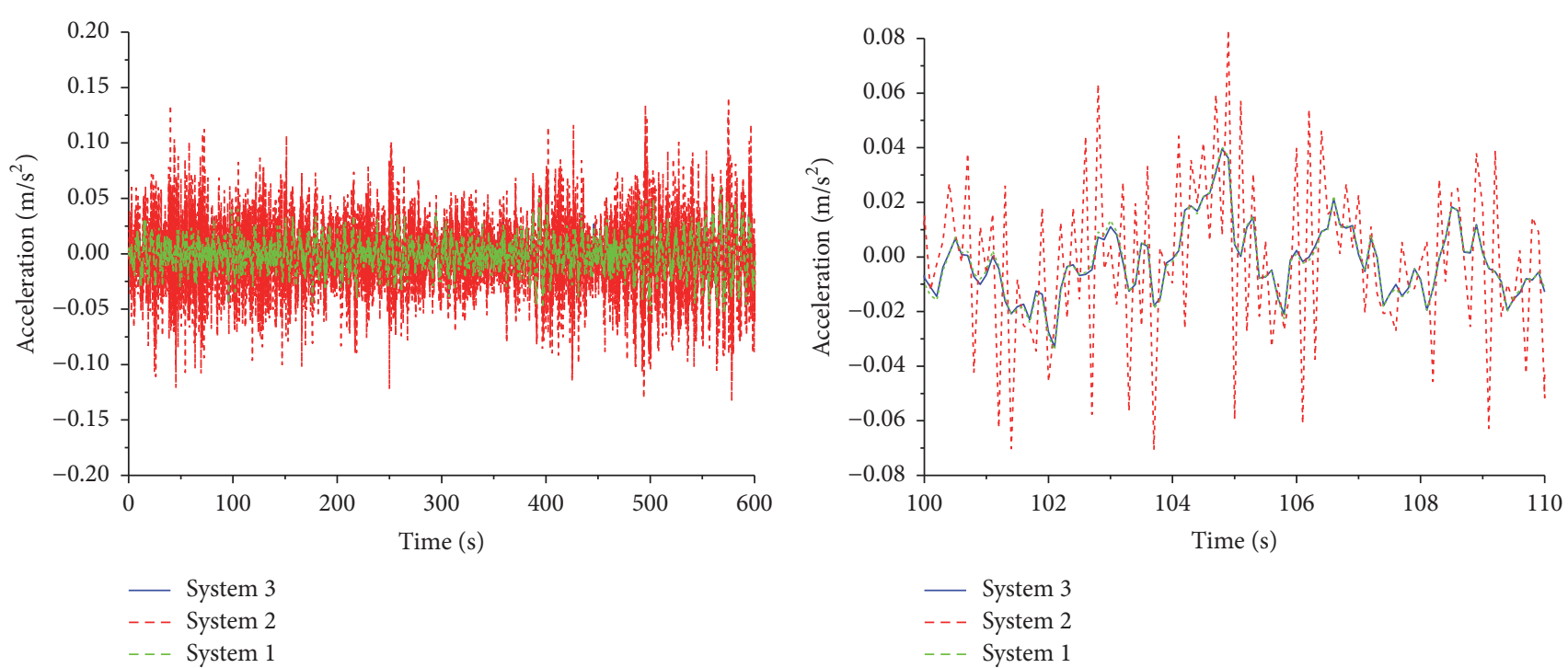

(a)

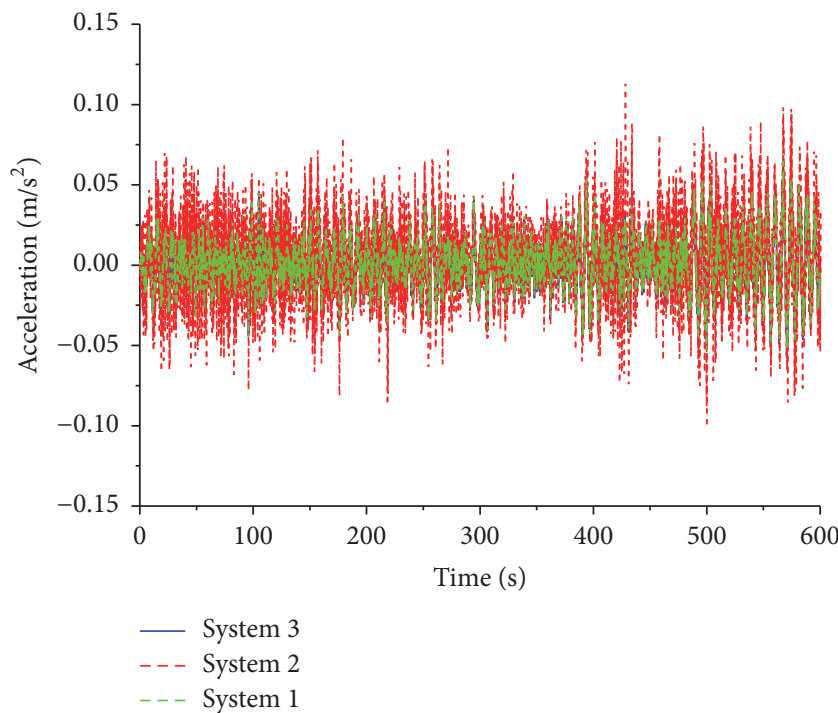

(c)

(b)

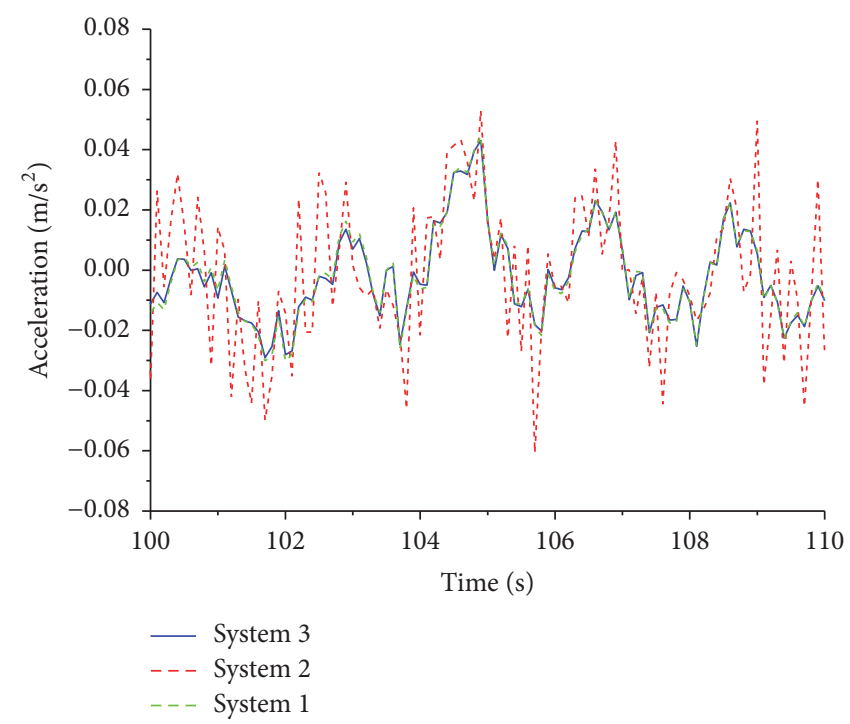

(d)

FIgURE 10: Comparison of structural acceleration in 87th and 91st floors of KK100: (a) and (c) 0-600 s; (b) and (d) $100-110 \mathrm{s.}$

nonconvex and difficult to be solved due to the filter gain matrix $G_{f}$ coupling with the different matrices of $X_{1}, X_{2}$. Therefore, variable substitution method cannot be used to linearize these constraints. A public Lyapunov matrix can be found to handle the problem [29].

$$
X=X_{1}=X_{2}
$$

The optimization problems from inequalities (39) to (40) can be summarized as

$\min \eta$

s.t. (1) Inequality (39); (2) Inequalities (40).
Both sides of the first inequality of inequalities (42) are pre- and postmultiplying $\operatorname{diag}\left\{X^{-1}, I, I\right\}$, defining $P=X^{-1}$, and then the matrix inequalities (42) are

$$
\begin{aligned}
\min & \eta \\
\text { s.t. } & {\left[\begin{array}{ccc}
P \widehat{A}+\widehat{A}^{T} P & P \widehat{B} & I \\
\widehat{B}^{T} P & -\gamma I & 0 \\
I & 0 & -\gamma I
\end{array}\right]<0, } \\
& {\left[\begin{array}{cc}
-Q & P^{-1} \\
P^{-1} & -P^{-1}
\end{array}\right]<0, } \\
& \operatorname{trace}(Q)<\eta^{2} .
\end{aligned}
$$




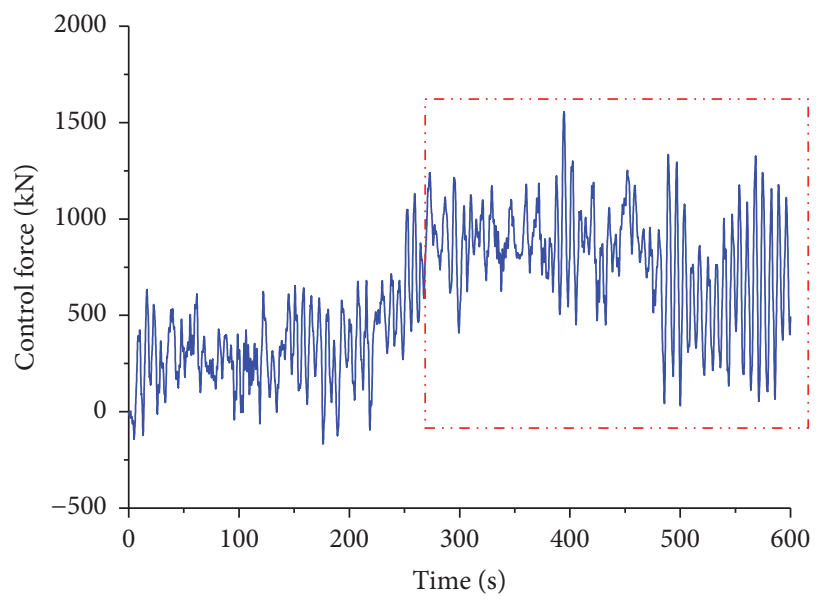

(a)

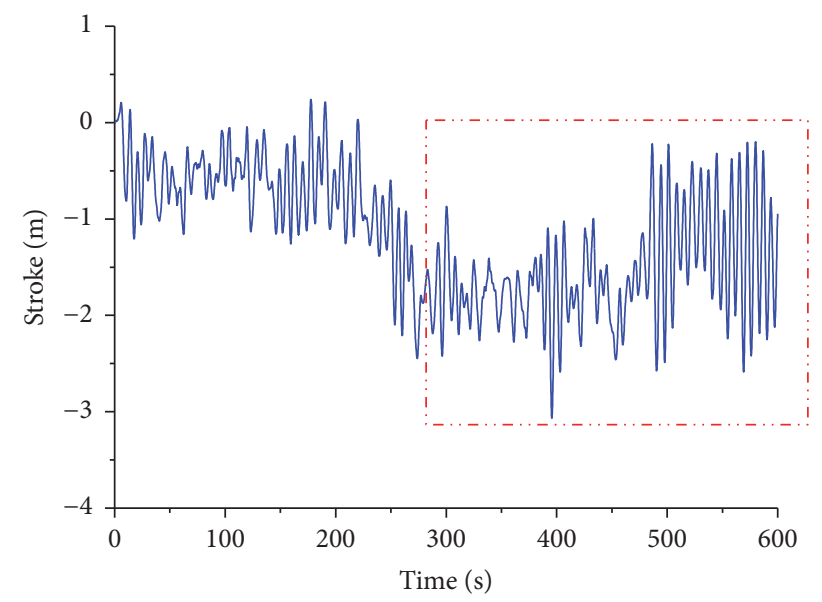

(b)

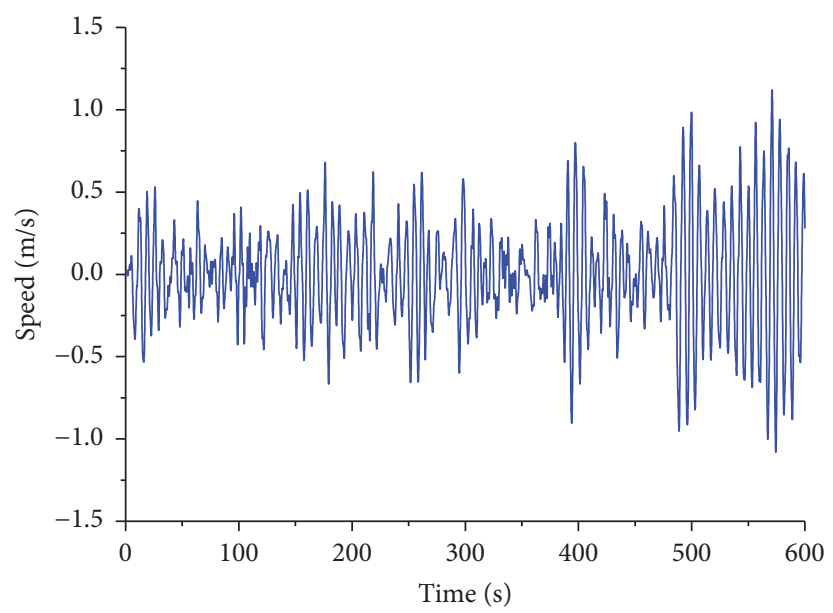

(c)

FIGURE 11: AMD parameters of the system with a Kalman filter: (a) AMD control forces, (b) AMD strokes, and (c) AMD speeds.

Substituting (37) into inequalities (43) leads to

$$
\begin{aligned}
& \min \eta \\
& \text { s.t. }\left[\begin{array}{ccc}
(A-B G)^{T} P+P(A-B G)-\left(P G_{f}\right)-\left(P G_{f}\right)^{T} & P\left[B_{1}, I,-G_{f}\right] & I \\
{\left[B_{1}, I,-G_{f}\right]^{T} P} & -\gamma I & 0 \\
I & 0 & -\gamma I
\end{array}\right]<0 \text {, } \\
& {\left[\begin{array}{cc}
-Q & P^{-1} \\
P^{-1} & -P^{-1}
\end{array}\right]<0,} \\
& \text { trace }(Q)<\eta^{2} \text {. }
\end{aligned}
$$




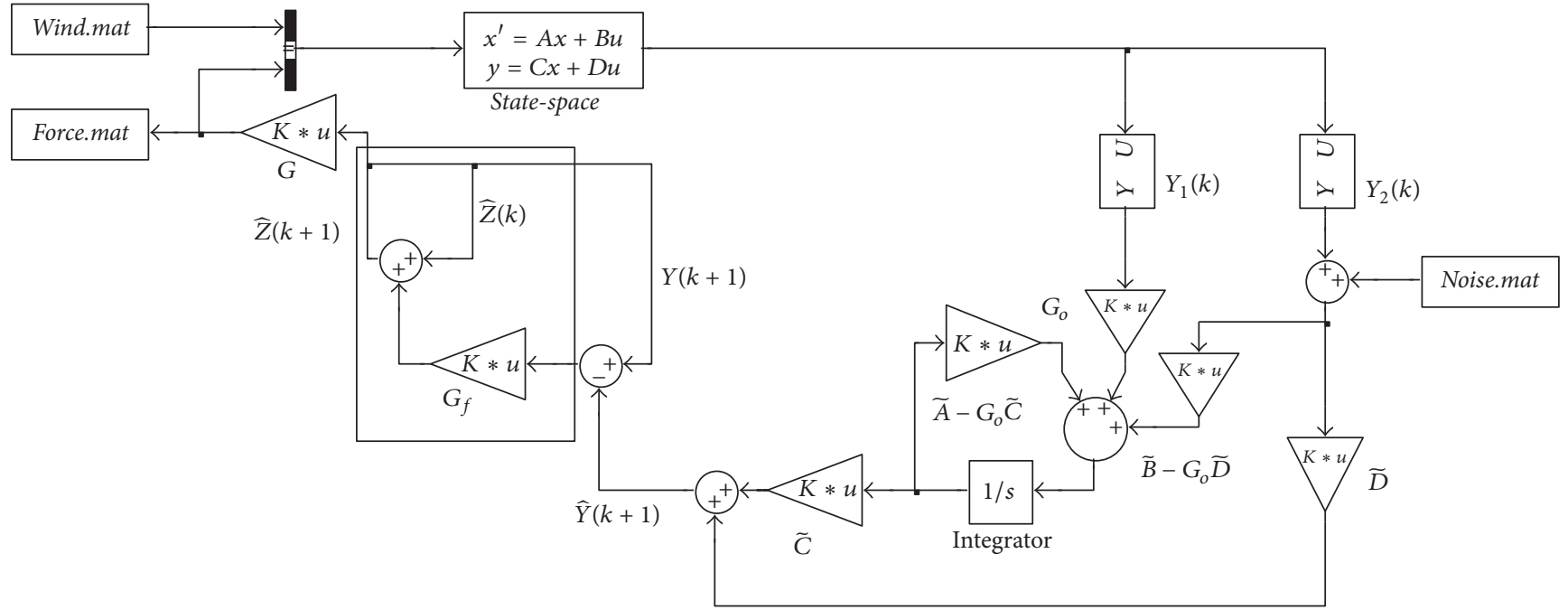

FIGURE 12: Simulink block diagram of the system with a LMI-based filter.

Define $N=P G_{f}$; then the constraint condition for solving the optimization problem (42) can be described as the following inequalities:

$$
\begin{aligned}
& {\left[\begin{array}{ccc}
(A-B G)^{T} P+P(A-B G)-N-N^{T} & {\left[P B_{1}, P,-N\right]} & I \\
{\left[P B_{1}, P,-N\right]^{T}} & -\gamma I & 0 \\
I & 0 & -\gamma I
\end{array}\right]} \\
& \quad<0, \\
& {\left[\begin{array}{cc}
-Q & P^{-1} \\
P^{-1} & -P^{-1}
\end{array}\right]<0,} \\
& \operatorname{trace}(Q)<\eta^{2} .
\end{aligned}
$$

The optimal solutions of $W, N$, and $X$ are obtained through the solver MINCX of LMI toolbox of Matlab, respectively. Then the matrices of optimal feedback gain of the controller and filter are

$$
G_{f}=P^{-1} N .
$$

The state-space equation of the LMI-based filter is

$$
\begin{aligned}
\dot{\bar{Z}}(t) & =(A-B G) \widehat{Z}(t)+G_{f}(Y-\widehat{Y}) \\
\widehat{Y}(t) & =\widehat{Z}(t) \\
G_{f} & =P^{-1} N .
\end{aligned}
$$

A LMI-based filter of discrete systems can be written as

$$
\begin{aligned}
\widehat{Z}(k+1) & =\widehat{Z}(k)+G_{f}[Y(k+1)-\widehat{Y}(k+1)] \\
\widehat{Y}(k+1) & =\widehat{Z}(k+1) \\
Y(k+1) & =\widehat{Y}(k) \\
G_{f} & =P^{-1} N .
\end{aligned}
$$

A Simulink block diagram of the rebuilding control system with a LMI-based filter shown in Figure 12 is designed to consider the negative influence of noise, but it does not depend on statistical properties of noise. The symbol inside the solid box in Figure 12 represents the LMI-based filter. Its gain $G_{f}$ is different with the Kalman filter gain. In LMI-based filter, since the discrete-time step is short, the actual state $Y(k+1)$ can be replaced by the estimated state $\widehat{Y}(k)$ [36].

The LMI-based filter shown as (48) is designed by ensuring that $\mathrm{H}_{2}$ norm $(\eta)$ of the input and output transfer function of the residue equation shown as (38) is minimum. $H_{\infty}$ norm $(\gamma)$ is taken as $1 \times 10^{-9}$. A numerical example of KK100 is presented to verify the effectiveness of the LMI-based filter. Systems 1 and 2 are the same as Section 2.3. System 3 with a LMI-based filter has been established. The structural acceleration and the AMD parameters of different control systems are shown in Figures 13-15, and the corresponding control effects are listed in Table 5. Moreover, a shorter return period wind has a more significant effect on noise signal. Therefore, a one-year return period simulated fluctuating wind load that acts on KK100 is also provided to illustrate the effectiveness of the proposed LMI-based filter.

Figures 13 and 14 give a comparison of the system without noise and the system with filtering noise under ten-year and one-year return period simulated fluctuating wind loads. The system with a LMI-based filter can obviously reduce the acceleration response of the structure. From Table 5, when ten-year return period wind load is considered, the maximum variations of the control effects between System 1 and System 3 are only $0.4264 \%$ and $0.5695 \%$. This fact can prove the effectiveness of the LMI-based filter. Since the gain is a global optimal solution, the observed control force and stroke of system 3 displayed in Figure 15 are stable as time goes on. Obviously, compared with the Kalman filter, the system with a LMIbased filter can filter out noise in the feedback signals and guarantee the stability of the AMD parameters. As one-year 


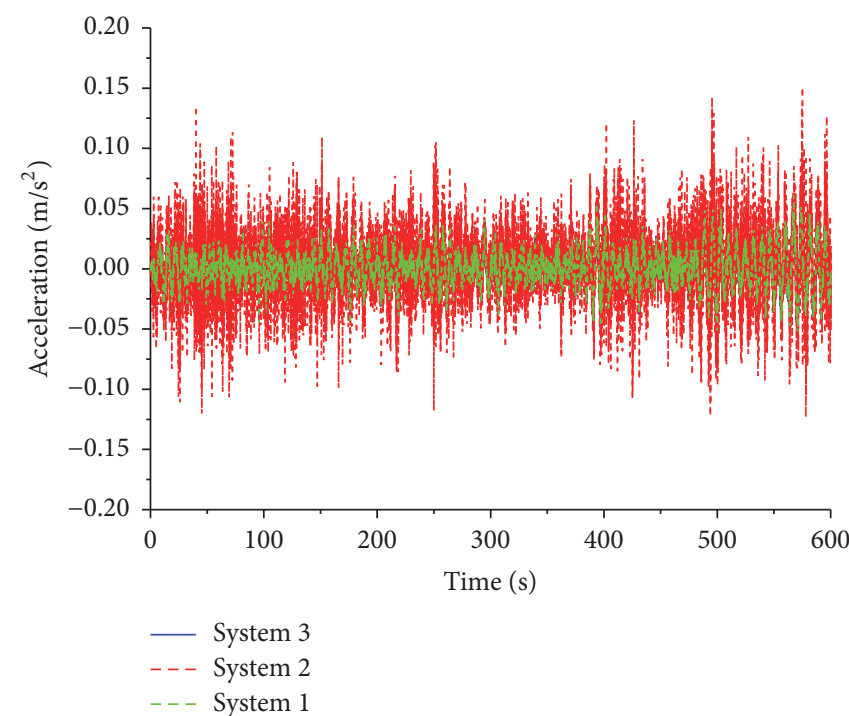

(a)

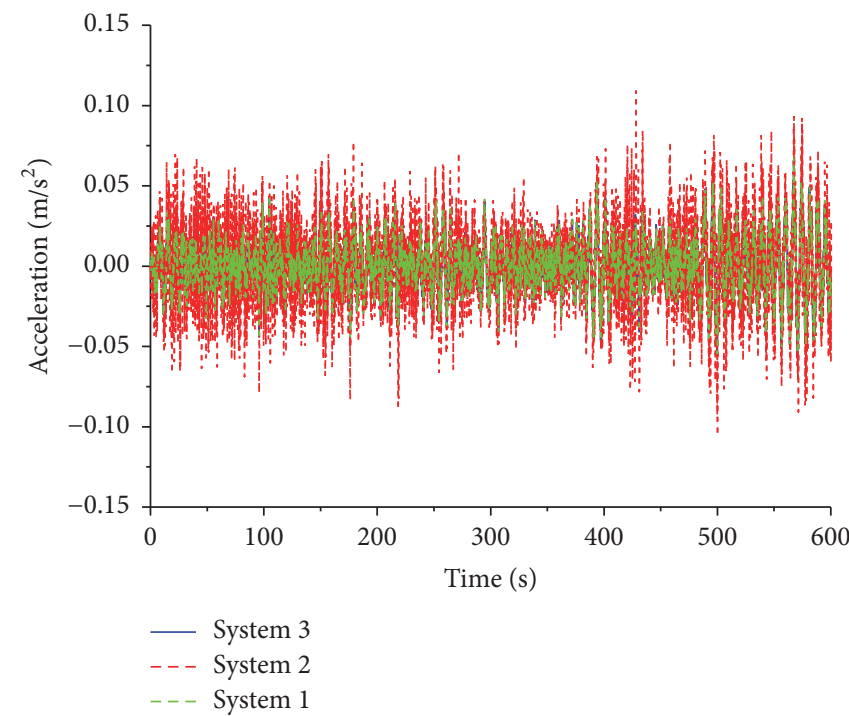

(c)

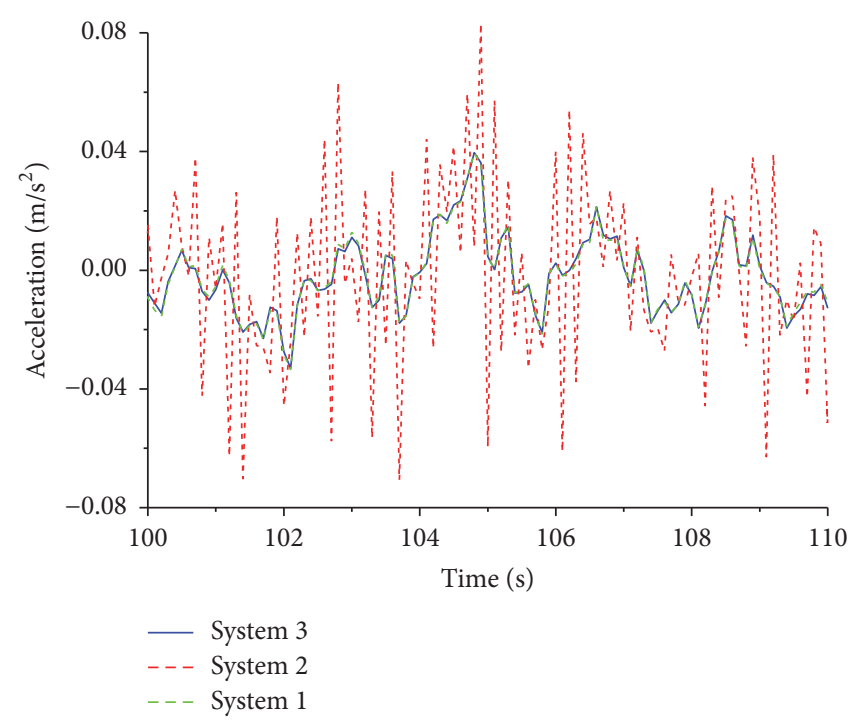

(b)

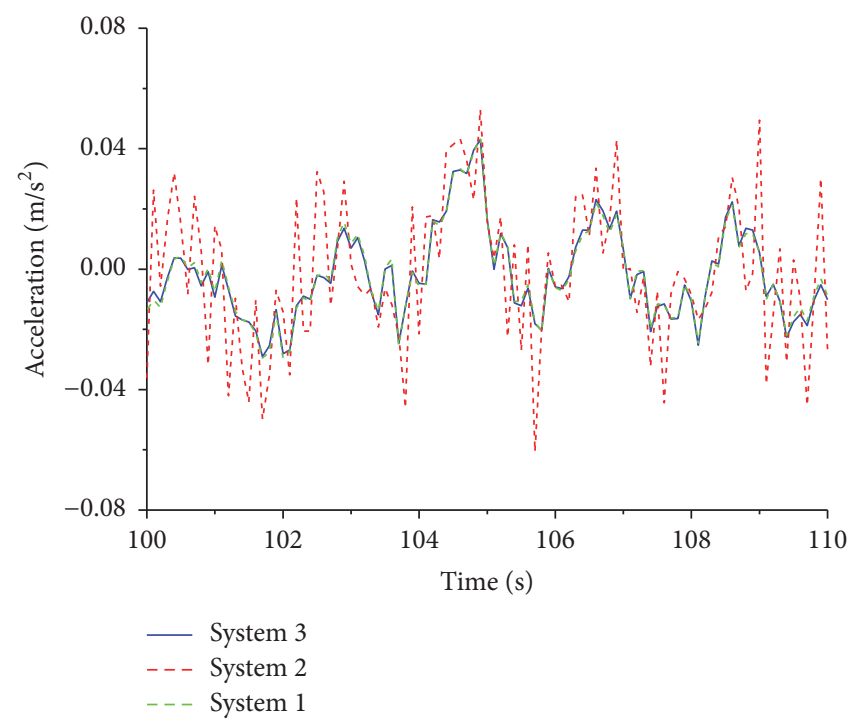

(d)

FIGURE 13: Comparison of structural acceleration in 87th and 91st floors of KK100 under ten-year return period wind load: (a) and (c) 0-600 s; (b) and (d) 100-110 s.

TABLE 5: Comparison of the acceleration control effects (\%).

\begin{tabular}{lcccccc}
\hline \multirow{2}{*}{ Floor } & \multicolumn{3}{c}{ Ten-year return period wind load } & \multicolumn{3}{c}{ One-year return period wind load } \\
& System 1 & System 2 & System 3 (LMI-based filter) & System 1 & System 2 & System 3 (LMI-based filter) \\
\hline 87th & 29.4691 & -24.5848 & 29.0427 & 30.6599 & -22.3591 & 29.9219 \\
91st & 28.2815 & -12.5420 & 27.7120 & 29.9043 & -10.3111 & 28.8975 \\
\hline
\end{tabular}

return period wind load is taken into account, the same results can be acquired.

\section{Experimental Verification}

This experimental system shown in Figure 16 consists of a four-storey steel frame made of steel and an AMD control device installed on the fourth floor [7]. Specifically, the AMD system mainly consisted of a servo motor, servo controller, an EtherCAT bus system, a dSPACE with a type of DS1103, and a computer. The loading system is composed of a reducer, an inverter, and an eccentric mass. The measurement system utilizes GT02 force balance accelerometers and Micro-Epsilon laser displacement sensors to measure the horizontal acceleration and displacement of the structure along the minor-axis. Acceleration signals are collected by a controller and used as 

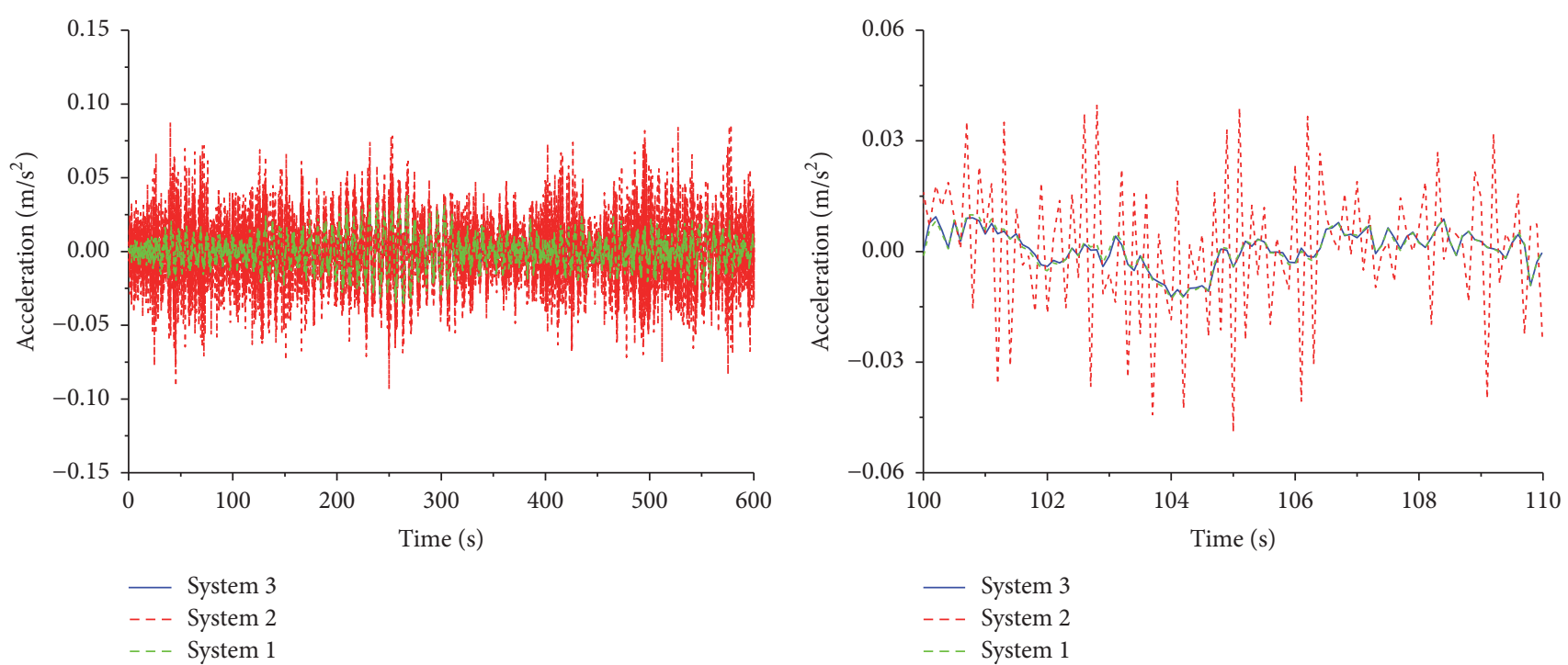

(a)

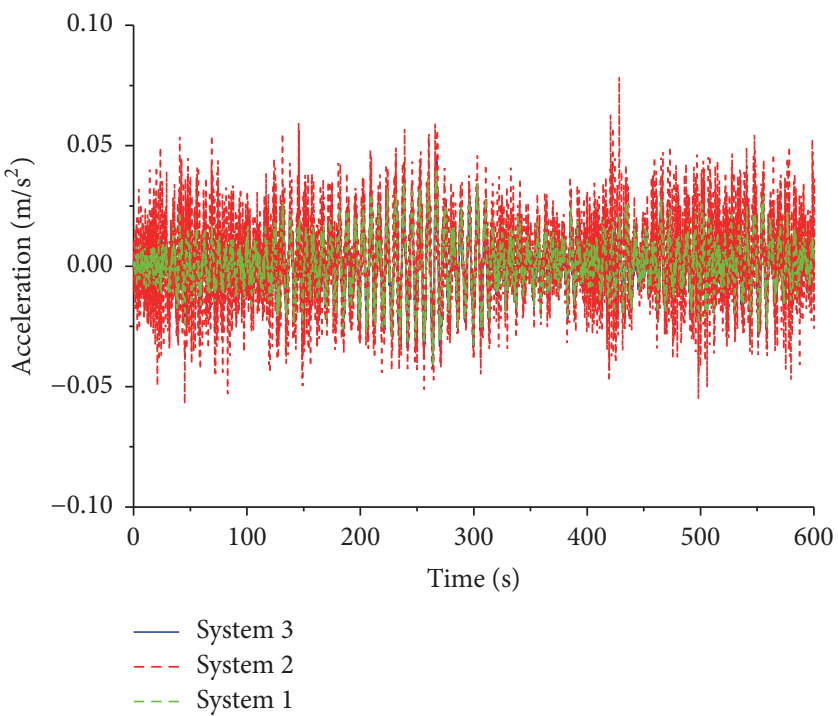

(c)

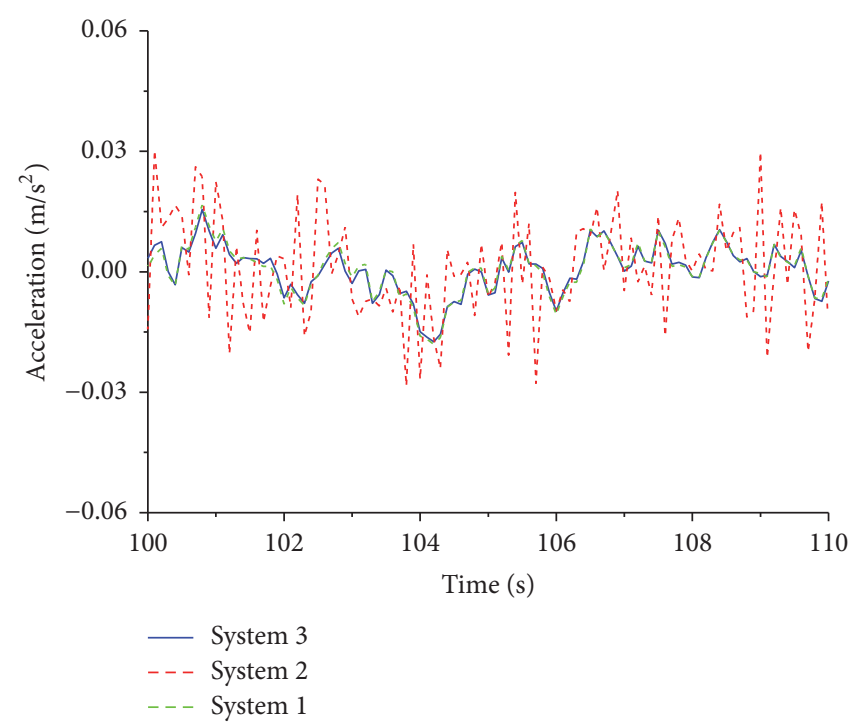

(d)

FIGURE 14: Comparison of structural acceleration in 87th and 91st floors of KK100 under one-year return period wind load: (a) and (c) 0-600 s; (b) and (d) 100-110 s.

the feedback signal to calculate the real-time control forces through a designed observer. An EtherCAT bus system can be used to transmit the forces to the servo motor. The displacement signals of the second, third, and fourth floors are used to verify the control effectiveness.

Signal obtained from GT02 force balance accelerometer includes noise and is processed by wavelet transformation to acquire the actual part in this experiment. Based on the measured and the actual signal, the estimate of the state can be obtained by the state observer, and the difference between the actual state and the estimated state is defined as the measurement noise $w_{2}$ of the system. Thus, covariance matrix of the measurement noise $R$ can be solved. Additionally, since the output of the Kalman filter is assumed as the system state, so $Q=R$ is set up. Then, the characteristics of noise in this accelerometer can be understood. A Kalman filter can be designed to the experimental system based on the above statistics. Meanwhile, a presented LMI-based filter is also designed to the system. A Simulink block diagram of the observer-based experimental control system with different filters shown in Figure 17 is established.

The structural responses and AMD parameters of different control systems with or without noise are shown in Figures 18 and 19. The duration of each scenario is $300 \mathrm{~s}$, and the figures only give data in $30 \mathrm{~s}$. Table 6 presents the corresponding control effects and the values of AMD parameters. The results show that AMD control system without a filter increases the structural response and play a negative role. The displacement and acceleration control effects of the system are all negative. Therefore, it is important to design filters to 


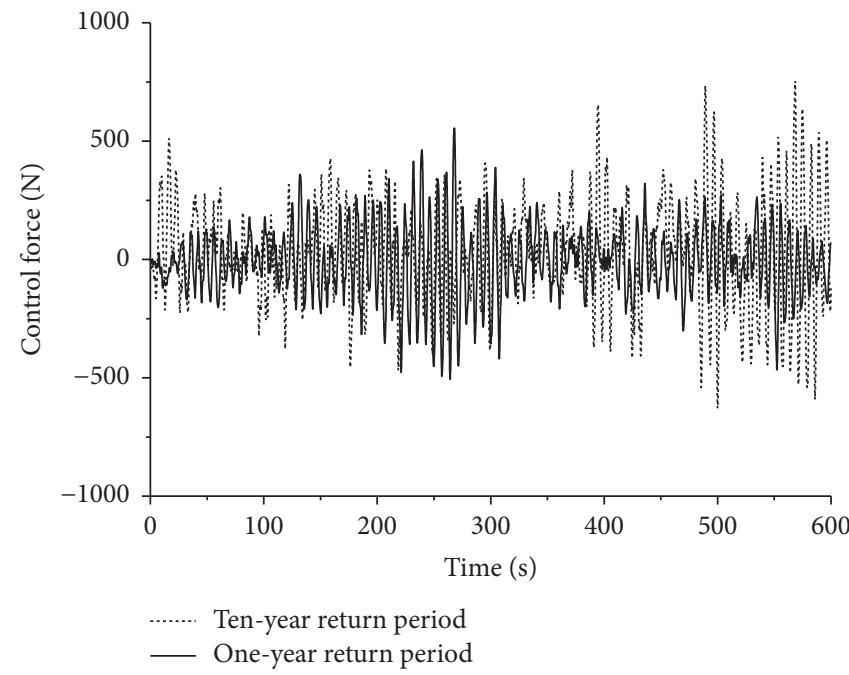

(a)

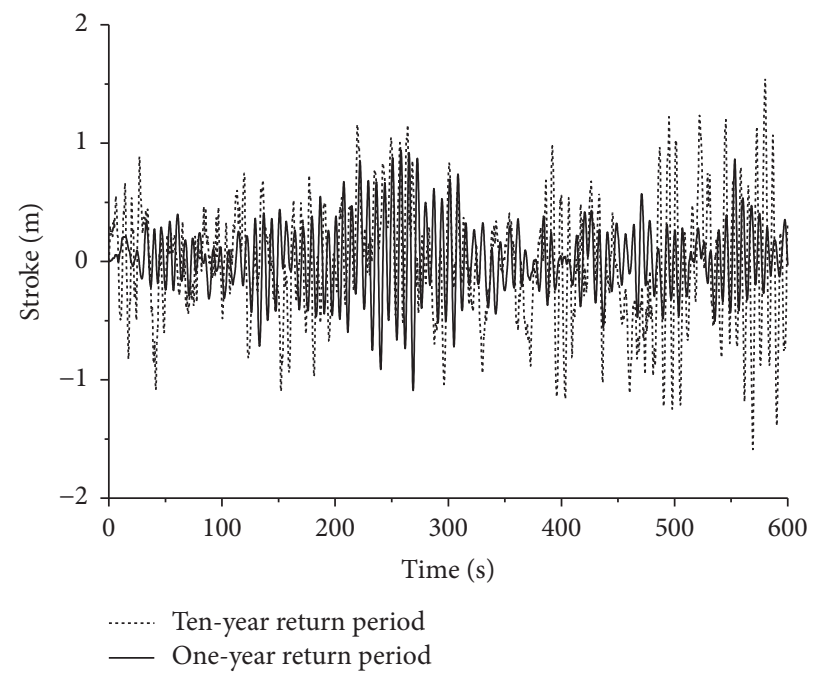

(b)

FIGURE 15: AMD parameters of the system with a LMI-based filter: (a) AMD control forces; (b) AMD strokes.

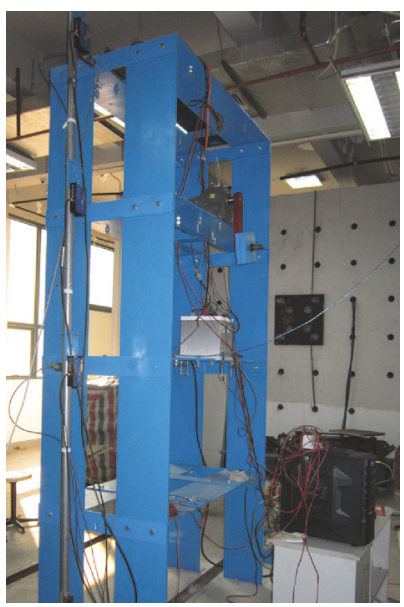

(a)

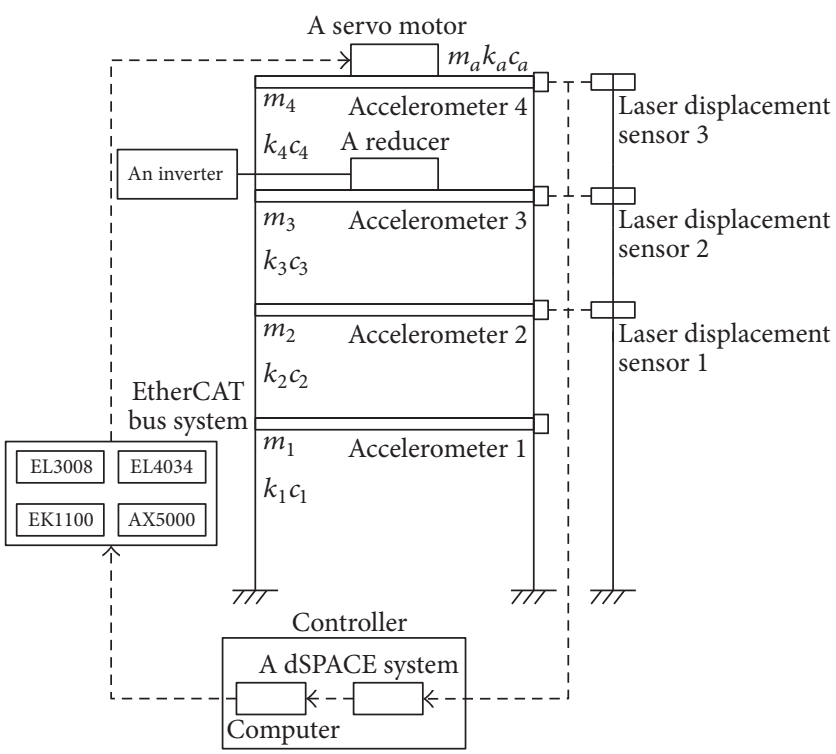

(b)

FIGURE 16: Pictures of the steel frame structure: (a) practicality; (b) exhibition.

TABLE 6: Control effectiveness of structural responses.

\begin{tabular}{|c|c|c|c|c|c|c|c|}
\hline \multirow{2}{*}{ Index } & & \multicolumn{2}{|c|}{ Without a filter } & \multicolumn{2}{|c|}{ A Kalman filter } & \multicolumn{2}{|c|}{ A LMI-based filter } \\
\hline & & Displacement & Acceleration & Displacement & Acceleration & Displacement & Acceleration \\
\hline \multirow{3}{*}{ Control effect (\%) } & 2nd floor & -13.5934 & -12.2130 & 20.4993 & 64.2662 & 19.0997 & 66.0015 \\
\hline & 3rd floor & -13.0100 & -4.0517 & 20.3007 & 38.2187 & 19.2022 & 42.8605 \\
\hline & 4th floor & -12.0078 & -11.3704 & 21.7973 & 62.4459 & 20.4427 & 69.2452 \\
\hline Control forces $(\mathrm{N})$ & & \multicolumn{2}{|c|}{19.3319} & \multicolumn{2}{|c|}{20.3221} & \multicolumn{2}{|c|}{16.1615} \\
\hline Strokes $(\mathrm{m})$ & & \multicolumn{2}{|c|}{0.1671} & \multicolumn{2}{|c|}{0.1694} & \multicolumn{2}{|c|}{0.1059} \\
\hline
\end{tabular}




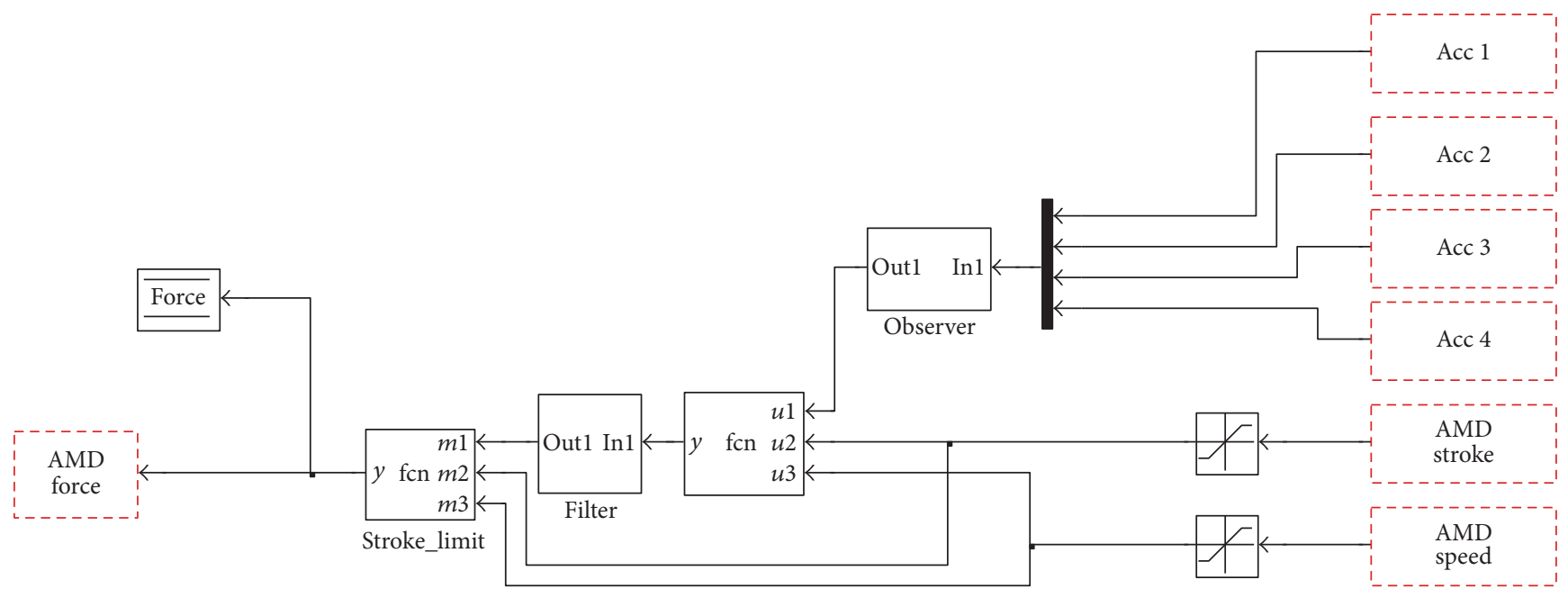

FIGURE 17: Simulink block diagram of the experimental system.

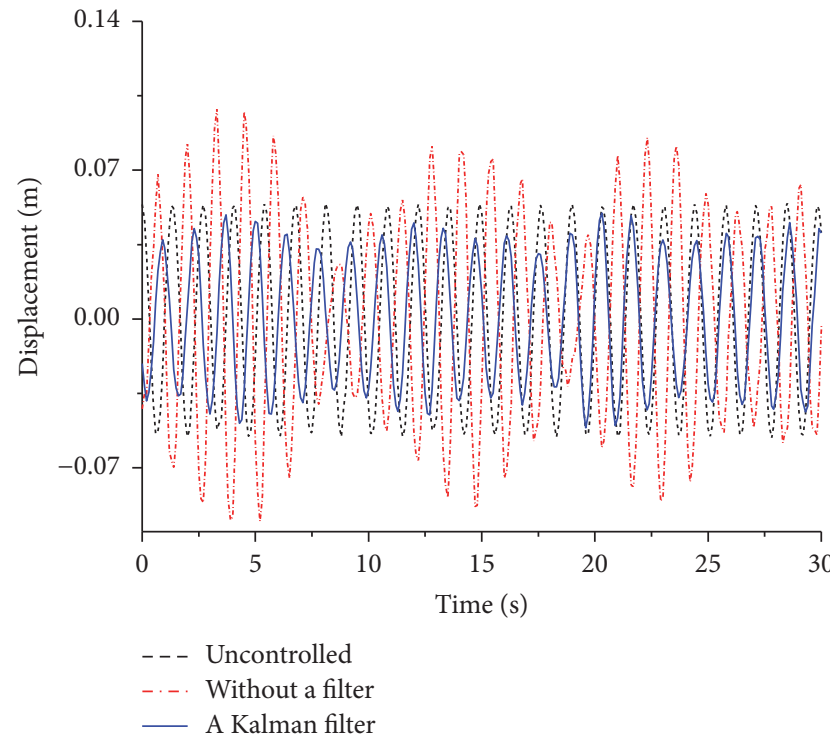

(a)

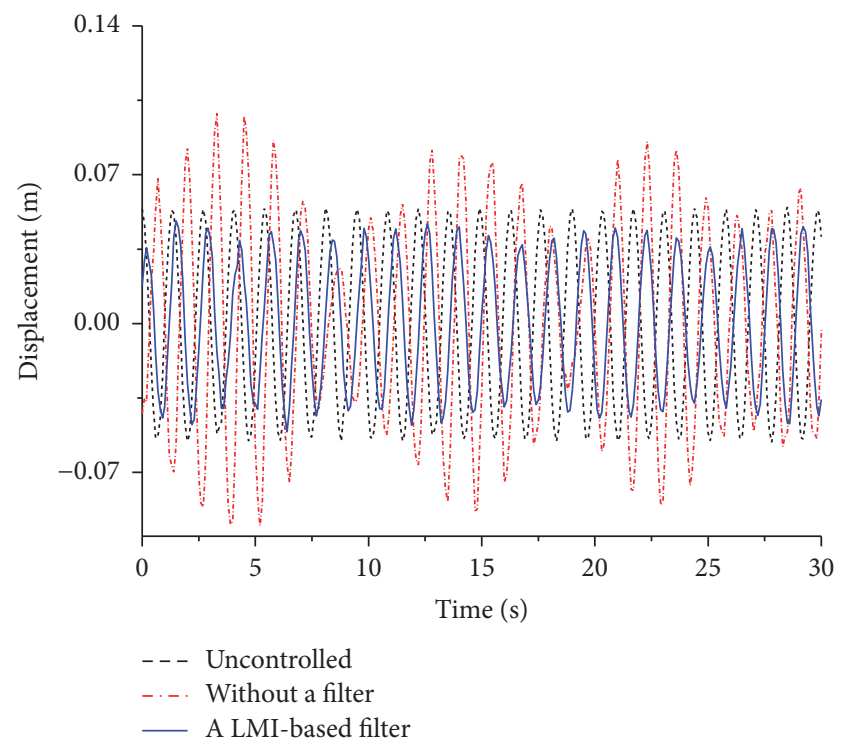

(c)

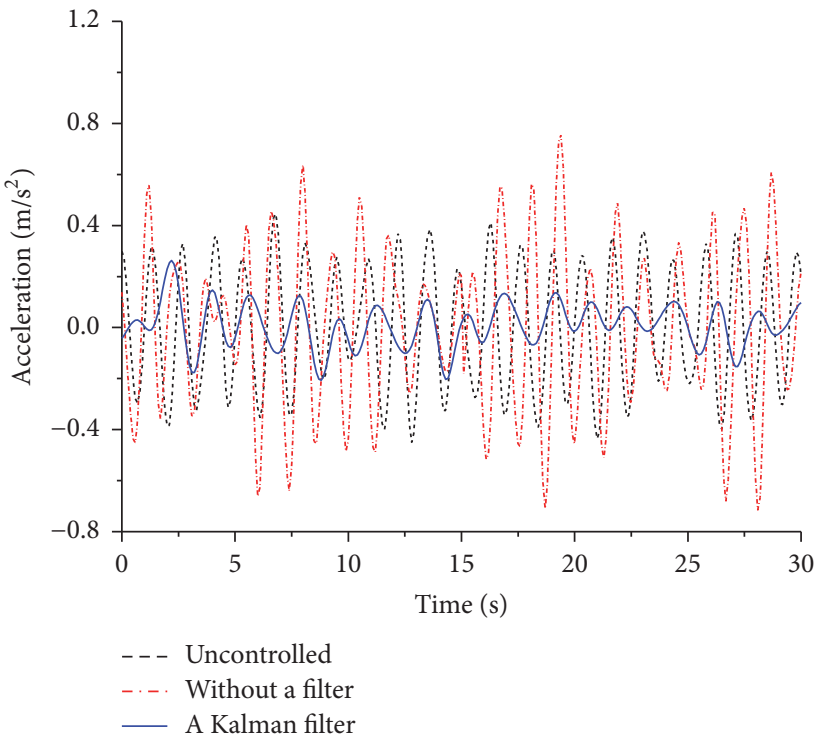

(b)

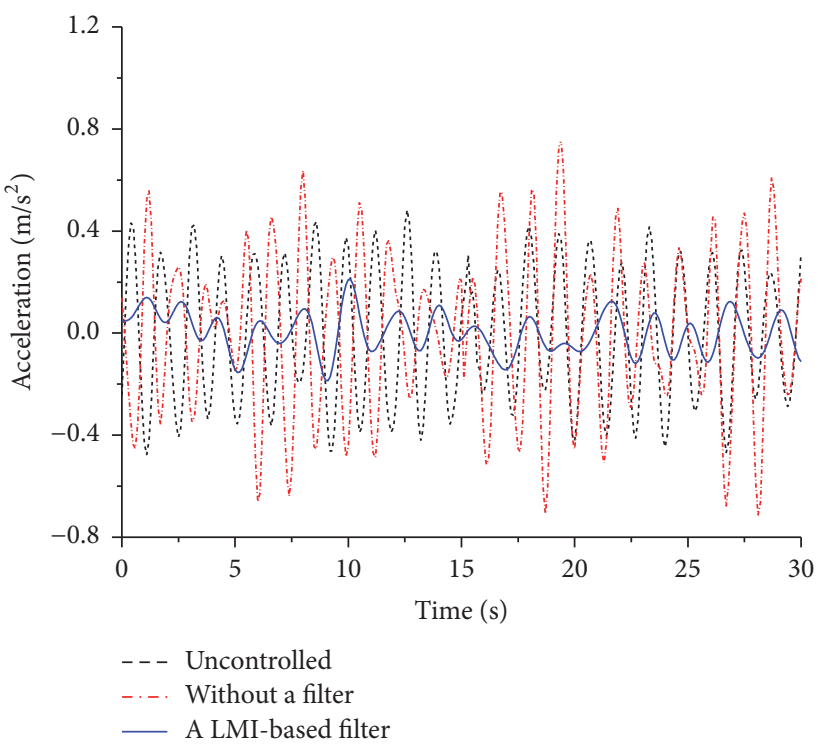

(d)

FIGURE 18: Comparison of structural responses in 4th floor of the experimental system: (a) and (c) displacement; (b) and (d) acceleration. 


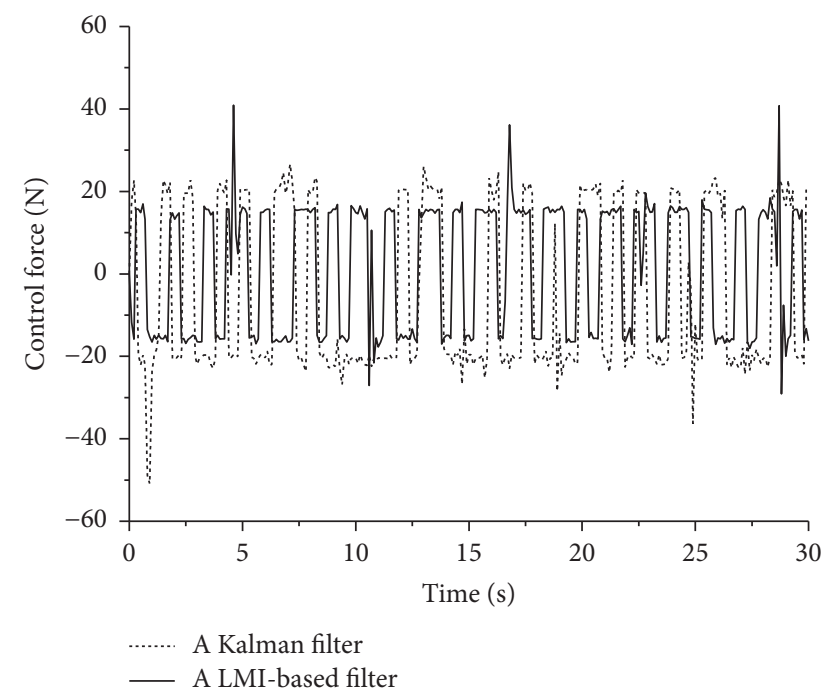

(a)

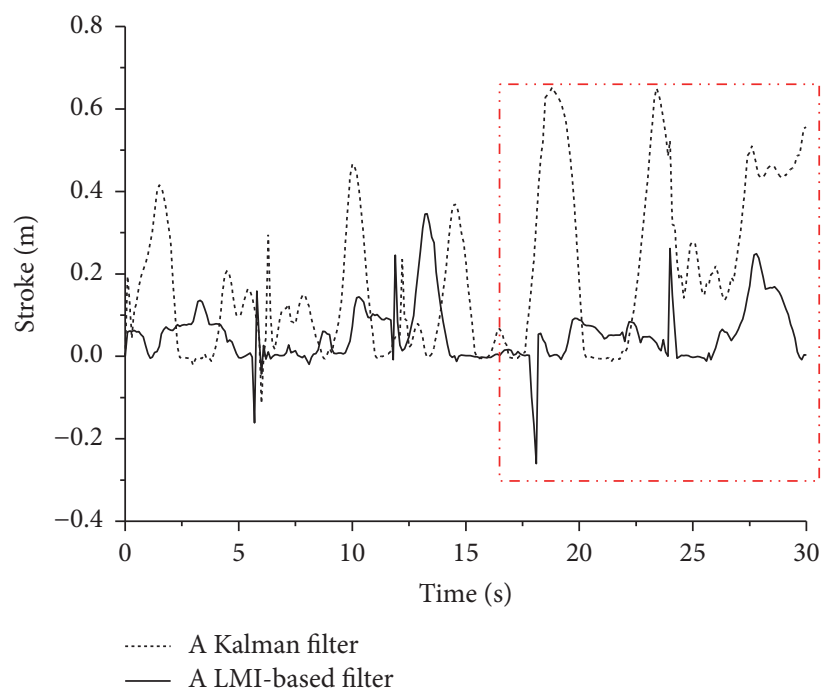

(b)

FIGURE 19: Comparison of AMD parameters of the experimental system: (a) AMD control forces. (b) AMD strokes.

isolate noise. The control effects of the systems with two different filters are all obviously consistent with each other, and these systems can obviously restrain the structural responses. However, the LMI-based filter maintains the AMD parameters in an appropriate range compared with the Kalman filter, and the AMD parameters decrease by $4.1406 \mathrm{~N}$ and $0.0635 \mathrm{~m}$.

Because of the interaction between the AMD system and the structure and the coupling between the horizontal and vertical vibrations of the structure, the structural responses do not completely obey the sine law under a sinusoidal load. Since the acceleration control needs high frequency control force that stimulates the structural high-order modes and AMD device is placed on the fourth floor of the structure, the control effect of the third floor has an opposite high-order phase with the second and fourth floor and is significantly less than the control effects of other floors.

\section{Conclusions}

The paper mainly discusses how to reduce the adverse influence of noise on high-rise buildings with AMD systems. A Kalman filter and a LMI-based filter are all presented for AMD systems with noise. Finally, a numerical example and an experiment are presented to verify the effectiveness of the proposed method. The main conclusions are as follows.

(1) MARMA method is successfully used to simulate a fluctuating wind load, whose wind speed power spectrum is similar to Davenport spectrum in a suitable frequency band.

(2) The original controller and the observer-based controller can obviously reduce the wind-induced acceleration responses. And the observer-based control system has the same control effects and stable AMD parameters as the former.

(3) A Kalman filter and a LMI-based filter are all designed in this paper. The control system with these above filters is consistent with the control system without noise, which indicates that these filters are effective.
(4) However, the control system with a Kalman filter is strongly dependent on the statistical properties of noise, and its selected Kalman filter gain is not a global optimal solution. As a result, its AMD parameters lose stability.

(5) Optimization of filter gain is accomplished based on LMI approach. Therefore, the control system with a LMIbased filter can guarantee the stability of its AMD parameters.

\section{Conflicts of Interest}

The authors declare that there are no conflicts of interest regarding the publication of this paper.

\section{Acknowledgments}

The research described in this paper was financially supported by the National Key Research and Development Program of China (Grant no. 2016YFC0701102), the National Natural Science Foundations of China (Grant nos. 51378007 and 51538003), and the Shenzhen Technology Innovation Programs (Grant nos. JSGG20150330103937411 and JCYJ20150625142543473).

\section{References}

[1] H. Cao, A. M. Reinhorn, and T. T. Soong, "Design of an active mass damper for a tall TV tower in Nanjing, China," Engineering Structures, vol. 20, no. 3, pp. 134-143, 1998.

[2] M. Yamamoto, S. Aizawa, M. Higashino, and K. Toyama, "Practical applications of active mass dampers with hydraulic actuator," Earthquake Engineering and Structural Dynamics, vol. 30, no. 11, pp. 1697-1717, 2001.

[3] F. Ricciardelli, A. D. Pizzimenti, and M. Mattei, "Passive and active mass damper control of the response of tall buildings to wind gustiness," Engineering Structures, vol. 25, no. 9, pp. 11991209, 2003.

[4] Y. Ikeda, K. Sasaki, M. Sakamoto, and T. Kobori, "Active mass driver system as the first application of active structural control," 
Earthquake Engineering and Structural Dynamics, vol. 30, no. 11, pp. 1575-1595, 2001.

[5] B. Basu, O. S. Bursi, F. Casciati et al., "A European association for the control of structures joint perspective. recent studies in civil structural control accross europe," Structural Control and Health Monitoring, vol. 21, no. 12, pp. 1414-1436, 2014.

[6] J. Teng, H. B. Xing, Y. Q. Xiao, C. Y. Liu, H. Li, and J. P. Ou, "Design and implementation of AMD system for response control in tall buildings," Smart Structures and Systems, vol. 13, no. 2, pp. 235-255, 2014.

[7] J. Teng, H. B. Xing, W. Lu, Z. H. Li, and C. J. Chen, "Influence analysis of time delay to active mass damper control system using pole assignment method," Mechanical Systems and Signal Processing, vol. 80, pp. 99-116, 2016.

[8] H. Kheloufi, A. Zemouche, F. Bedouhene, and M. Boutayeb, "A new observer-based stabilization method for linear systems with uncertain parameters," in Proceedings of the European Control Conference (ECC '13), pp. 1120-1125, Zurich, Switzerland, July 2013.

[9] H. R. Karimi and M. Chadli, "Robust observer design for takagisugeno fuzzy systems with mixed neutral and discrete delays and unknown inputs," Mathematical Problems in Engineering, vol. 2012, Article ID 635709, 13 pages, 2012.

[10] A. Golabi, M. T. Beheshti, and M. H. Asemani, "Dynamic observer-based controllers for linear uncertain systems," Journal of Control Theory and Applications, vol. 11, no. 2, pp. 193-199, 2013.

[11] M. Farza, M. M'Saad, T. Maatoug, and M. Kamoun, "Adaptive observers for nonlinearly parameterized class of nonlinear systems," Automatica. A Journal of IFAC, the International Federation of Automatic Control, vol. 45, no. 10, pp. 2292-2299, 2009.

[12] D. Saoudi, M. Chadli, C. Mechmeche, and N. Benhadj Braiek, "Unknown input observer design for fuzzy bilinear system: an LMI approach," Mathematical Problems in Engineering, vol. 2012, Article ID 794581, 21 pages, 2012.

[13] D. Krokavec and A. Filasová, "A reduced-order TS fuzzy observer scheme with application to actuator faults reconstruction," Mathematical Problems in Engineering, vol. 2012, Article ID 951953, 25 pages, 2012.

[14] D. Liu, Y. Huang, D. Wang, and Q. Wei, "Neural-networkobserver-based optimal control for unknown nonlinear systems using adaptive dynamic programming," International Journal of Control, vol. 86, no. 9, pp. 1554-1566, 2013.

[15] N. Boizot, E. Busvelle, and J.-P. Gauthier, "An adaptive high-gain observer for nonlinear systems," Automatica. A Journal of IFAC, the International Federation of Automatic Control, vol. 46, no. 9, pp. 1483-1488, 2010.

[16] S. Jeon and M. Tomizuka, "Benefits of acceleration measurement in velocity estimation and motion control," Control Engineering Practice, vol. 15, no. 3, pp. 325-332, 2007.

[17] F. Qin, X. Dai, and J. E. Mitchell, "Effective-SNR estimation for wireless sensor network using Kalman filter," Ad Hoc Networks, vol. 11, no. 3, pp. 944-958, 2013.

[18] A. Alessandri, M. Baglietto, and G. Battistelli, "A maximumlikelihood Kalman filter for switching discrete-time linear systems," Automatica. A Journal of IFAC, the International Federation of Automatic Control, vol. 46, no. 11, pp. 1870-1876, 2010.

[19] M. Karasalo and X. Hu, "An optimization approach to adaptive Kalman filtering," Automatica. A Journal of IFAC, the International Federation of Automatic Control, vol. 47, no. 8, pp. 17851793, 2011.
[20] R. Peesapati, S. L. Sabat, K. P. Karthik, J. Nayak, and N. Giribabu, "Efficient hybrid Kalman filter for denoising fiber optic gyroscope signal," Optik, vol. 124, no. 20, pp. 4549-4556, 2013.

[21] Z. Liu, J. Wang, and Y. Xue, "Interacting multiple sensor filter," Signal Processing, vol. 92, no. 9, pp. 2180-2186, 2012.

[22] Y. H. Yu, "Combining $H_{\infty}$ filter and cost-reference particle filter for conditionally linear dynamic systems in unknown nonGaussian noises," Signal Processing, vol. 93, no. 7, pp. 1871-1878, 2013.

[23] W. J. Qi, P. Zhang, and Z. L. Deng, "Robust weighted fusion Kalman filters for multisensor time-varying systems with uncertain noise variances," Signal Processing, vol. 99, no. 1, pp. 185-200, 2014.

[24] B. Fridholm, T. Wik, and M. Nilsson, "Kalman filter for adaptive learning of look-up tables with application to automotive battery resistance estimation," Control Engineering Practice, vol. 48, pp. 78-86, 2016.

[25] F. Alonge, F. D’Ippolito, A. Fagiolini, and A. Sferlazza, “Extended complex Kalman filter for sensorless control of an induction motor," Control Engineering Practice, vol. 27, no. 1, pp. 1-10, 2014.

[26] O. Rosén, A. Medvedev, and T. Wigren, "Parallelization of the Kalman filter on multicore computational platforms," Control Engineering Practice, vol. 21, no. 9, pp. 1188-1194, 2013.

[27] S. W. Pan, H. Y. Su, J. Chu, and H. Wang, "Applying a novel extended Kalman filter to missile-target interception with APN guidance law: A benchmark case study," Control Engineering Practice, vol. 18, no. 2, pp. 159-167, 2010.

[28] S. Boyd, L. E. Ghaoui, E. Feron, and V. Balakrishnan, Linear matrix inequalities in system and control theory, vol. 15 of SIAM Studies in Applied Mathematics, Society for Industrial and Applied Mathematics (SIAM), Philadelphia, Pa, USA, 1994.

[29] L. Yu, Robust Control-Linear Matrix Inequalities Approach, Tsinghua University Press, China, 2002.

[30] C. X. Qu, L. S. Huo, and H. N. Li, "Fault tolerant control for civil structures based on LMI approach," Mathematical Problems in Engineering, vol. 2013, Article ID 762385, 8 pages, 2013.

[31] E. J. Hannan, "The identification of vector mixed autoregressive-moving average system," Biometrika, vol. 56, pp. 223-225, 1969.

[32] J. P. Ou, Active, Semi-Active and Intelligent Control in Civil Engineering Structure, Science Press, 2003.

[33] G. Burgers, P. J. van Leeuwen, and G. Evensen, "Analysis scheme in the ensemble Kalman filter," Monthly Weather Review, vol. 126, no. 6, pp. 1719-1724, 1998.

[34] R. F. Souto and J. Y. Ishihara, "Robust kalman filter for discretetime systems with correlated noises," in Proceedings od the Mediterranean Conference on Control and Automation, (MED '08), pp. 1658-1662, fra, June 2008.

[35] J.-H. Ge, P. M. Frank, and C.-F. Lin, "Robust $H_{\infty}$ state feedback control for linear systems with state delay and parameter uncertainty," Automatica, vol. 32, no. 8, pp. 1183-1185, 1996.

[36] R. Panigrahi and B. Subudhi, "Performance enhancement of shunt active power filter using a Kalman filter based $H_{\infty}$ control strategy," IEEE Transactions on Power Electronics, pp. 1-9, 2016. 


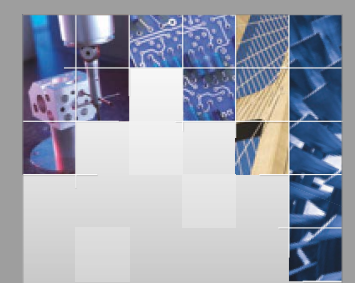

\section{Enfincering}
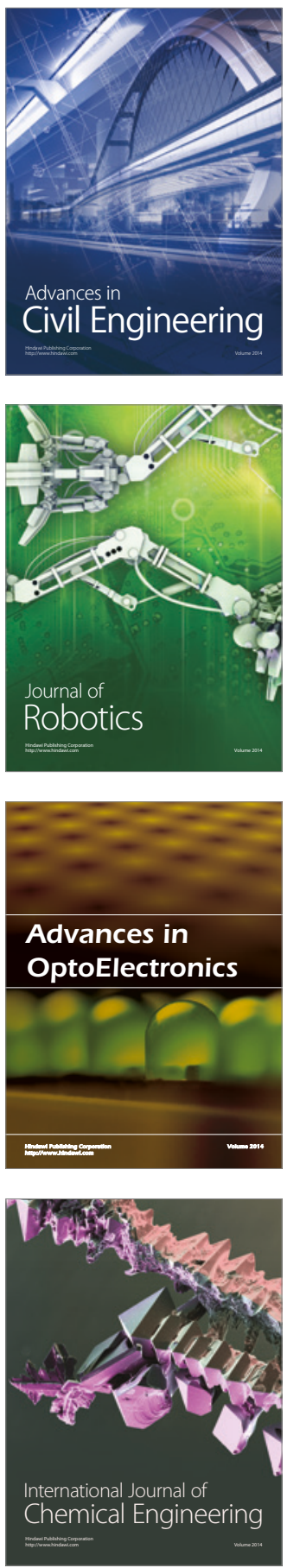

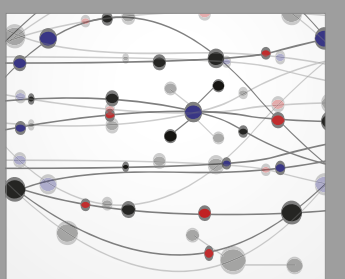

The Scientific World Journal

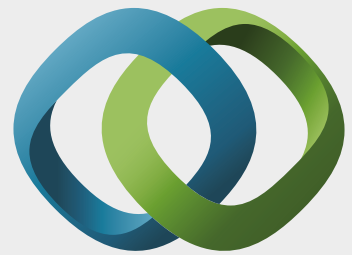

\section{Hindawi}

Submit your manuscripts at

https://www.hindawi.com
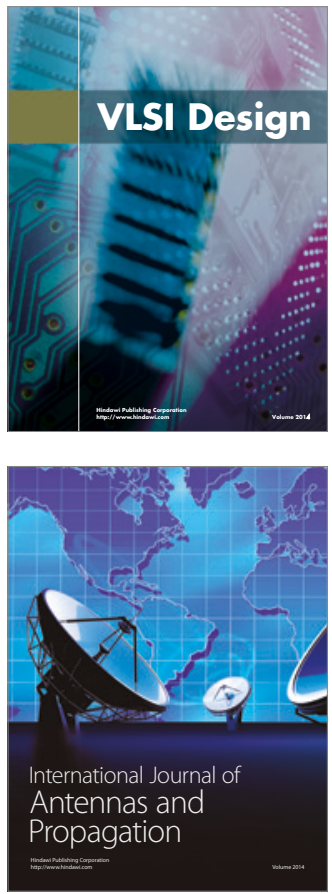

\section{Rotating}

Machinery
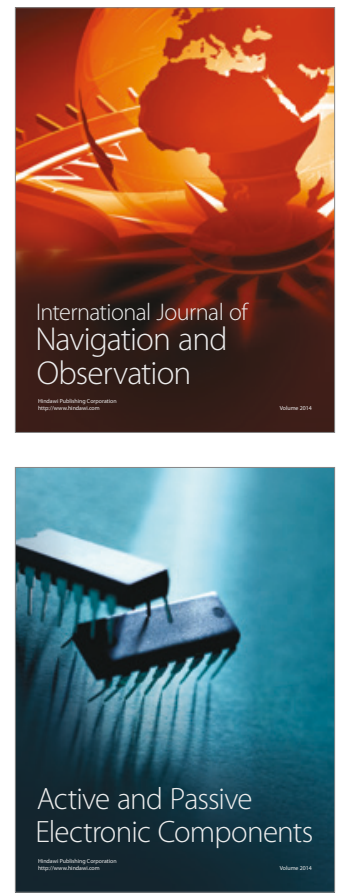
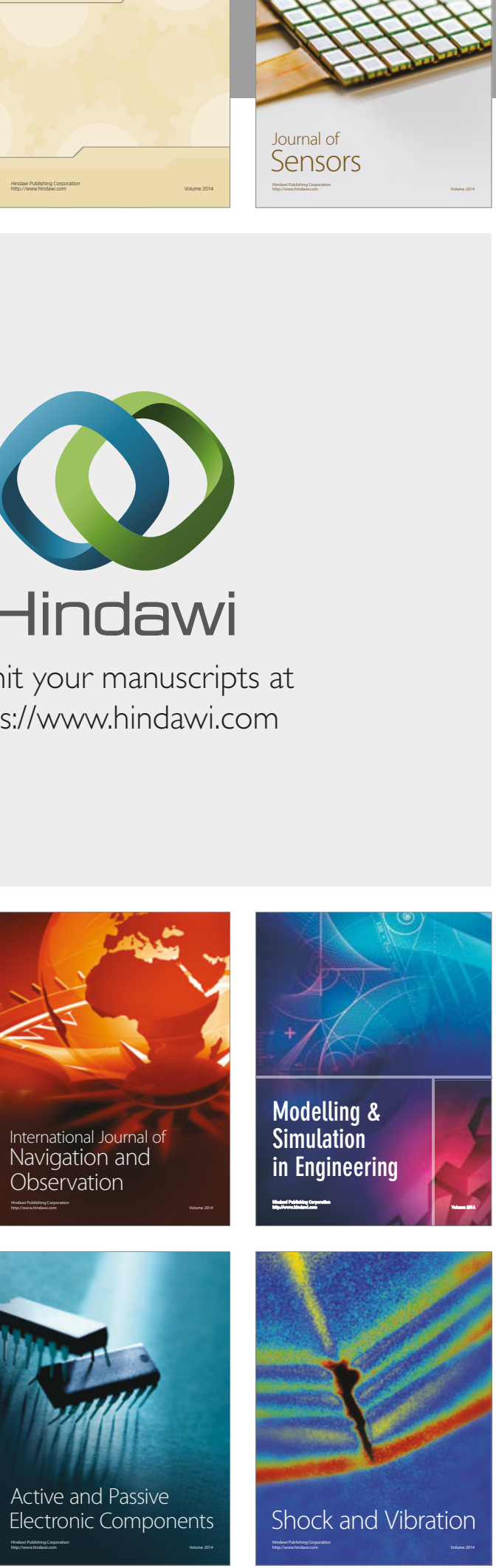
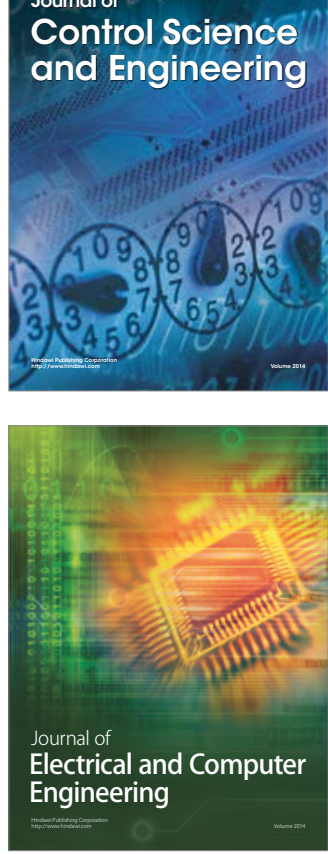

Distributed

Journal of

Control Science

and Engineering
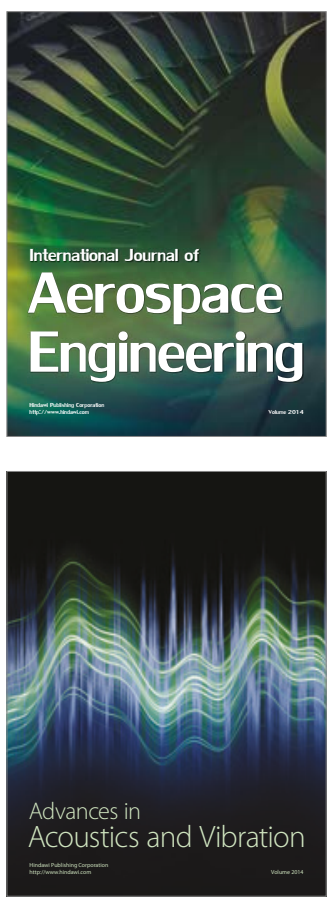

Sensor Networks 